\title{
EMPIRICAL ANALYSIS OF THE IMPACT STRENGTH OF TEXTILE KNITTED BARRIER MESHES
}

\author{
Zbigniew Mikołajczyk¹, Beata Szałek², Katarzyna Pieklak \\ 1 Lodz University of Technology, Faculty of Material Technologies and Textile Design, Department of Knitting Technology and Textile Machines, Lodz, \\ Poland, tel.: +48 426313331 , \\ 2 Department of Functional Materials, Łukasiewicz Research Network - Institute of Leather Industry, Lodz, Poland, tel.: +48 422536119 \\ ${ }^{*}$ Corresponding author. Email: zbigniew.mikolajczyk@p.lodz.pl, katarzyna.pieklak@p.lodz.pl \\ b.szalek@ips.lodz.pl
}

\begin{abstract}
:
The assumptions of instrumental methodology for measuring dynamic loads of knitted barrier meshes were defined. A test stand was built, original in terms of both mechanical construction and electronic measuring system, connected to a computer data analysis system. Maximum values of dynamic forces in the mesh fastening strings were determined. The correctness of the strain gauges construction and measurement data transmission systems was confirmed. Tests of multidirectional resistance to dynamic loads in the mesh fastening strings were carried out. The experiment involved dropping a ball with a mass of $5 \mathrm{~kg}$ and a diameter of $10 \mathrm{~cm}$, from a height of $1 \mathrm{~m}$ and $2 \mathrm{~m}$ onto the mesh surface. The potential impact energy equaled Ep1 $=49.05 \mathrm{~J}$ and Ep2 $=98.1 \mathrm{~J}$. The tests showed that the highest force values were observed for meshes with square-shaped a-jour structure, and for mesh with diamond-shaped a-jour geometry the force values were lower. A symmetrical forces distribution was observed in all the strings. The highest forces were recorded in the middle strings and the lowest in the outer ones. The conducted tests confirmed the correctness of the adopted constructional solutions of test stand for identification of dynamic stress distribution in mesh fastening strings. The developed method is a useful verification tool for numerical analysis of mechanical properties of barrier meshes.
\end{abstract}

\section{Keywords:}

Knitted barrier meshes, measurement methods of stresses in meshes, test stand of meshes, computer simulation

\section{Introduction}

\subsection{Instrumental method for evaluating multidirectional strength of barrier meshes}

Mesh products, regardless of their production technology, textile or non-textile, are subjected to numerous tests before they are approved for use. Technical openwork products are usually applied in the form of safety meshes or as safety elements in works performed at heights. They also constitute a large group of geotextiles, which are used in agriculture and fruit growing, packaging of agricultural products, elements of sports halls equipment, fishery industry, construction industry, and other fields.

\subsection{Characteristics of strength evaluation methods of barrier meshes}

The construction industry is the main application area of steel barrier meshes. Steel meshes currently available in the market are used: as reinforcements of concrete structures, in road engineering as mesh barriers, and in mining as elements supporting the rocks in the excavation to prevent their cracking and falling down of rock fragments. In the last category, these products are used in the form of a meshes made of the raw materials used in the production of textiles (e.g., PGG mesh composites made of polyester fibers) or of steel (typical mining grids) depending on the prevailing conditions. Such products are subjected to bending and tensile tests.

Checking the static load-bearing capacity and deformability of the mesh during the so-called "box test" is carried out on a specialized measuring stand [1]. This method is not regulated by any standards. It is used to evaluate static load-bearing capacity mainly for mine lining, chain-nodal meshes, and detent meshes, mounted on door frames (arched casing on which the rock foundation in the mine is supported) [1].

The strength test usually comprises the following stages:

- first, the mesh is appropriately placed,

- then the box is filled with aggregate and granite tiles with a total weight of $625 \mathrm{~kg}$,

- the box is placed in the test stand and five displacement sensors are attached to the steel mesh,

- During the second step, static load-bearing capacity and mesh deformability are measured when a loading force $F$ is applied (the aggregate and granite tiles) with displacement $\Delta \mathrm{l}$ as a function of time. During the test, the load increases 
a)

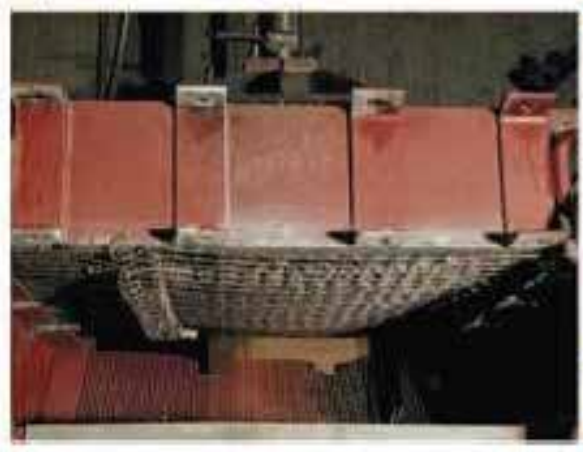

b)

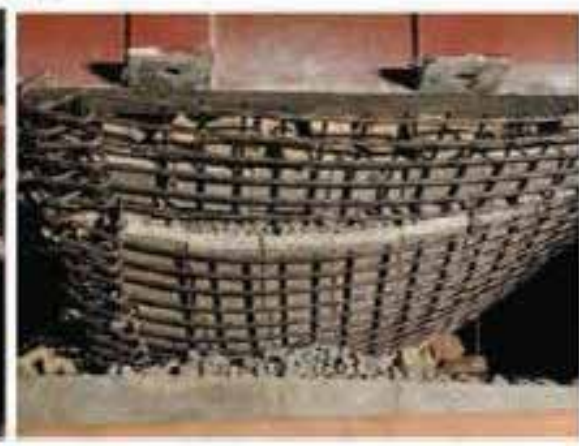

b)

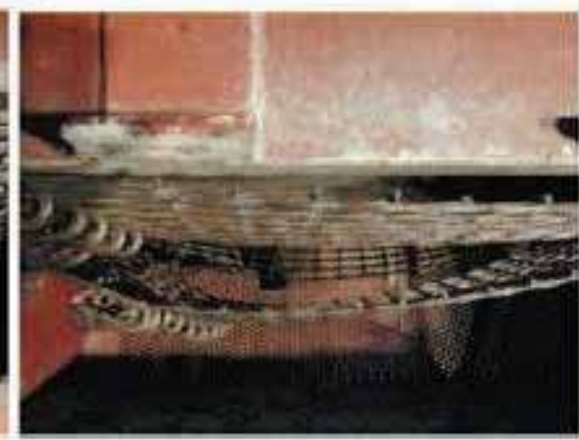

Figure 1. Subsequent phases of measuring deformations in welded wire mesh lining according to "box test" method: (a) mesh before test, (b) mesh after test, (c) mesh deformation and damage [1].

as a result of using a hydraulic servomotor which exerts additional pressure on the box,

- During the last stage of the test the obtained measurement results of the maximum force $F_{\text {max }}$ are noted and values of the work $\mathrm{W}$ and the resisting force $\mathrm{F}$, which the mesh generates during its deformation $L$ are determined $[2,3]$. Figure 1 shows the subsequent phases of mesh deflection analysis by the "box test" method.

The static method based on applying a certain force to the surface of the mesh is another method for evaluating mechanical strength of mesh linings used in mining industry. The presented measuring system is used for testing welded detent meshes and the application areas and research methodology are described in PN-G-15050 standard. This standard defines the testing process of and the construction of the measuring stand (Figure 2). Using this procedure, the mesh load-bearing capacity is evaluated similarly as in the "box test" method. In order to correctly attach the mesh on the surface of the rock during excavation, a simulation is carried out to optimize the fastening method of the detent mesh and to evaluate its mechanical parameters. In the numerical experiment, the type of support for the mesh anchored in the rock and the individual elements of mesh structure are analyzed. As a result of the conducted tests, deformations and stress distribution are obtained. Figure 3 illustrates examples of reduced stress distribution for a single wire and Figure 4 shows stress distribution in the mesh surface.

Based on numerical tests, some conclusions can be drawn related to the method of mesh attachment and its mechanical properties: effort, rigidity, mechanical strength (dynamic loadbearing capacity), and thus its effectiveness and functionality $[2,3,5]$. In case of composite meshes used in mining industry made of non-steel raw materials, the testing process is identical. Composite meshes are placed in the holders of the measuring stand, separated from each other by a distance of $1 \mathrm{~m}$. The samples have a width of $500 \mathrm{~mm}$ and a length of about $1.2 \mathrm{~m}$, and are adjusted to the spacing of the supports (Figure 5).

The WASM type tensile testing machine is used to determine mechanical properties of meshes used in the mining industry and evaluate static load-bearing capacity of steel meshes.

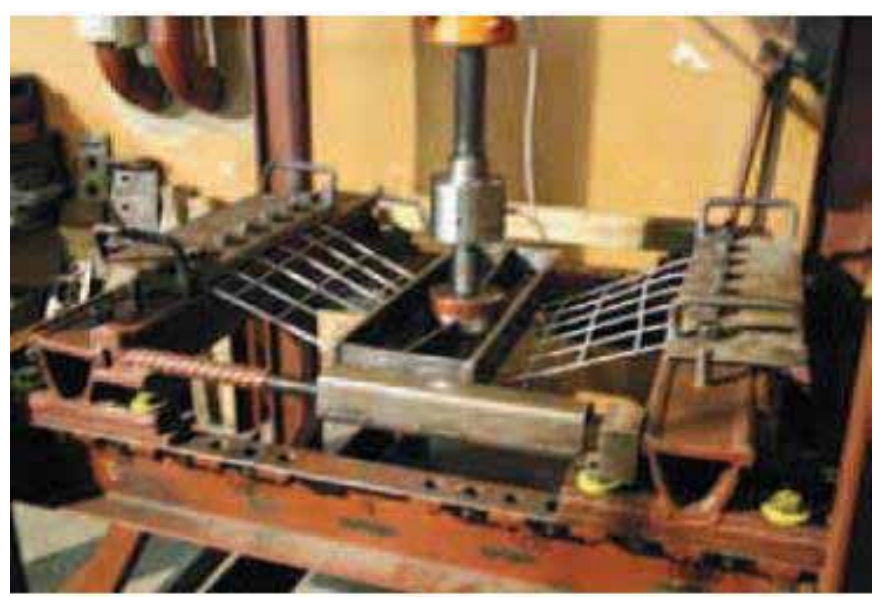

Figure 2. Test stand for evaluating load-bearing capacity of mesh lining [2].

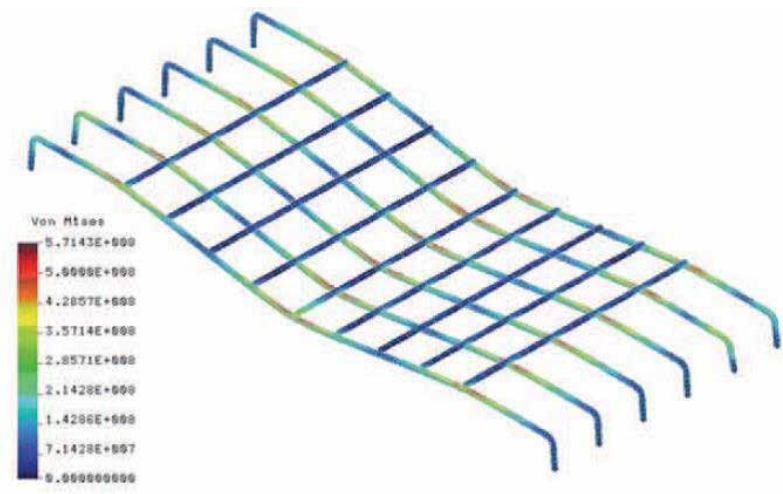

Figure 3. Reduced stress distribution in mesh surface partially supported on catches [3].

The measuring device described by Morton (2007) is shown in Figure 6. The device consists of two steel frames, the bottom one used to support the sample and the upper one for generating the load. The mesh sample is fixed in a rigid frame. In this method the mesh sample is fastened by attaching the edge eyelets with hooks (Figure 7). The auger lift mechanism, which is fixed on the reaction frame, is driven at constant speed ( $4 \mathrm{~mm} / \mathrm{min}$ ) causes mesh deformation.

The force is measured with a strain gauge attached between the lead-screw shaft and the ball-shaped load point. 

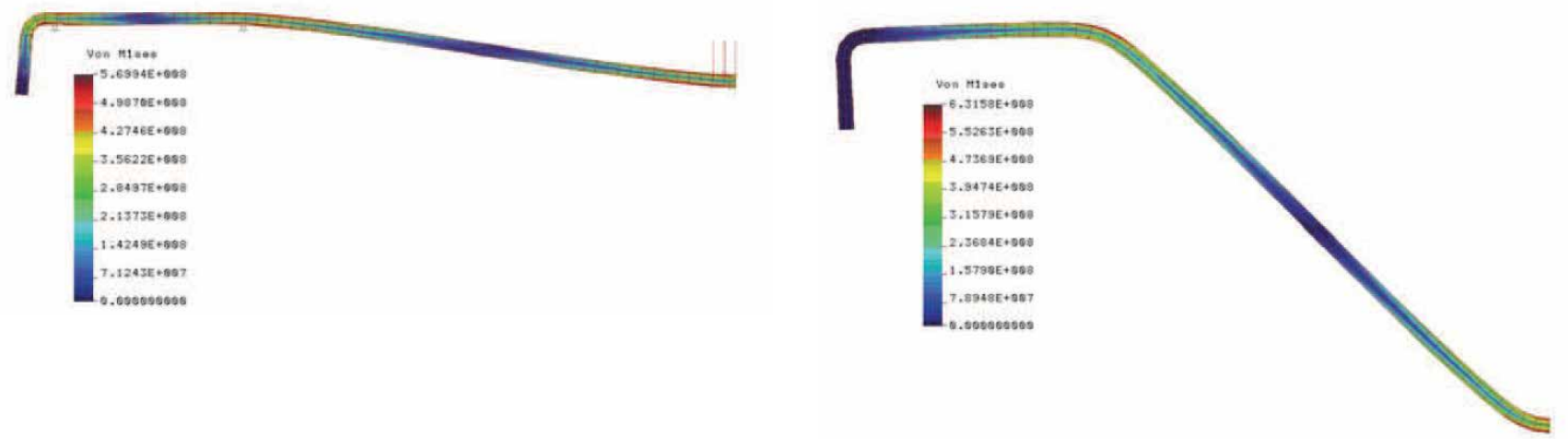

Figure 4. Reduced stress distribution in $1 / 2$ wires forming mesh lining for different loading forces: (a) with applied force, (b) after bending [3, 4].

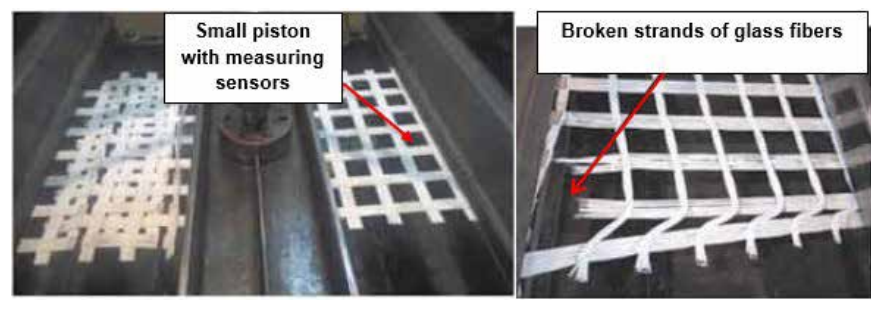

Figure 5. Measuring static load bearing capacity of composite meshes $[5,6]$.

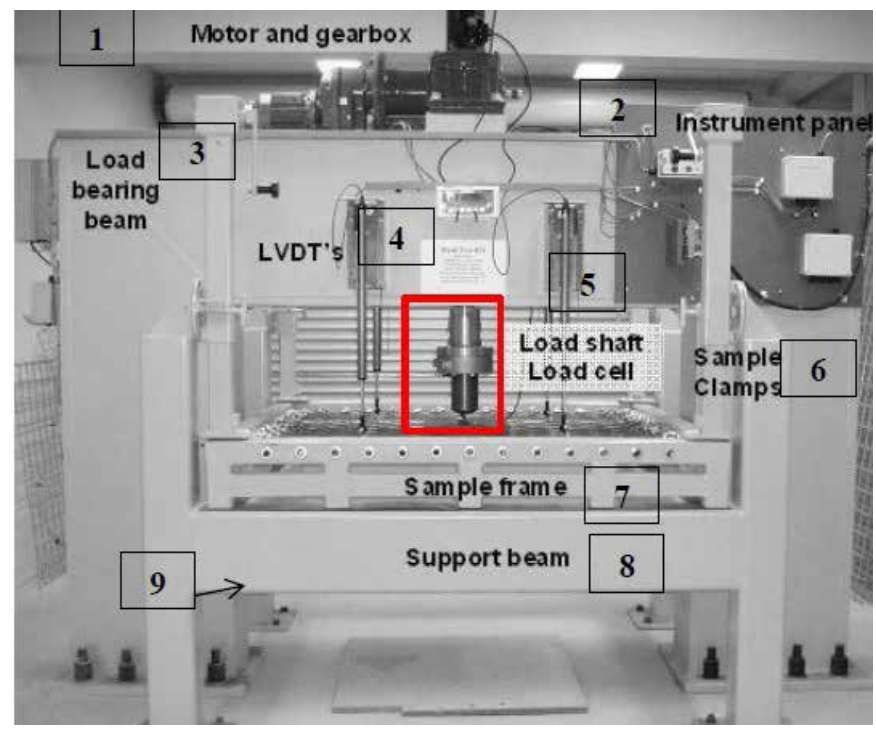

Figure 6. WASM instrument for static testing of meshes intended for mining industry: 1-motor and gear, 2-instrument panel, 3-load bearing beam, 4-transmission of electrical signals using a low-voltage differential signal in symmetrical copper cables, 5-load shaft with a charger, 6-sample clamps, 7-sample frame, 8-support beams, 9steel plate $[5,7]$.

Another well-known method for evaluating load-bearing capacity of steel meshes is based on using a machine which can dynamically record the amount of deformation and stresses occurs in the tested sample. The machine was developed by Player Company (2004) and is shown in Figure 8. The testing device consists of a drop beam placed in between four guide rails. The frame supporting the mesh is screwed to the supporting structure. The mesh is held in its place with the help of a threaded bar, a pan, and eyebolts, similar to the configuration of a standard static system.

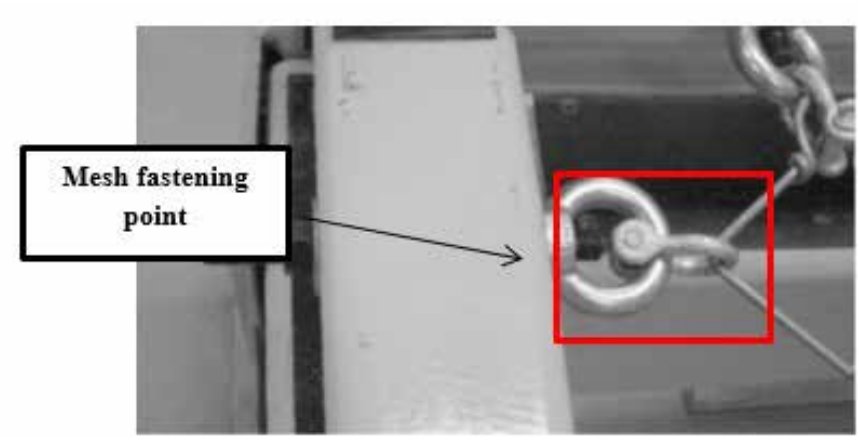

Figure 7. Mesh fastening with the help of hooks $[5,8]$.

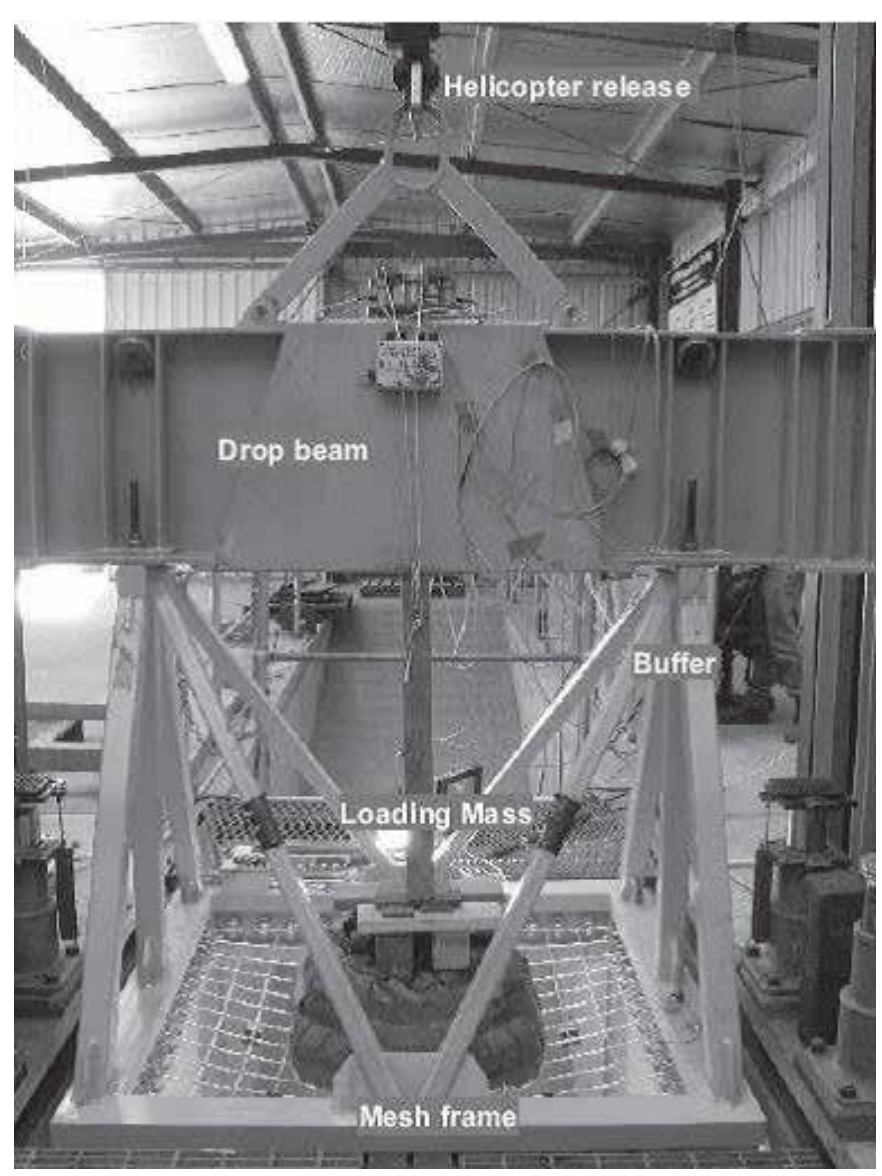

Figure 8. Machine for dynamic strength testing of steel meshes used in mining industry $[4,9]$. 
The loading mass is placed in the center of the truss and consists of a bag in the shape of a "pyramid" filled with steel balls $(0.5$ or 1 ton). The loading surface of the bag is $650 \mathrm{~mm} \times 650 \mathrm{~mm}$. The drop beam with the system of strings, to which the load is attached, is "dropped" from a certain height, thus generating dynamic loading on the mesh surface.

Computer software, advanced instrumentation, and a fast video camera are used to record the data. Data acquisition is carried out at a speed of 25,000 samples/second per channel $[5,10]$.

Swiss company Geobrugg, offer a wide range of products used in road safety engineering, also conducts research in the field of strength testing of steel barrier meshes with different geometry of the a-jour structure. The company tests mechanical parameters of barrier meshes using concrete blocks with an appropriate weight dropped vertically from a specified height. The first test of this type was carried out in May 2001 in quarries in Walenstadt, Switzerland [11, 12]. The test consisted of dropping a block of $9,640 \mathrm{~kg}$ from a height of $43 \mathrm{~m}$. It was

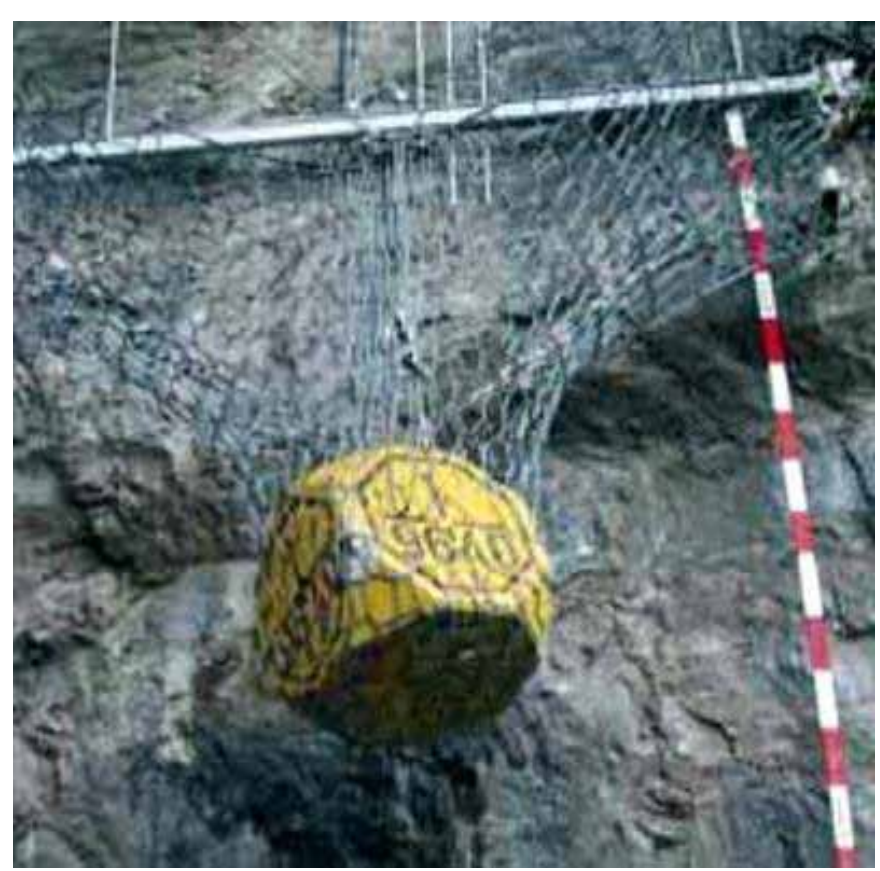

Figure 9. Vertical impact test with concrete block weighting 9,640 kg and speed of $90 \mathrm{~km} / \mathrm{h}$ dropped from a height of $32 \mathrm{~m}$ onto Geobrugg barrier mesh [13].

a)

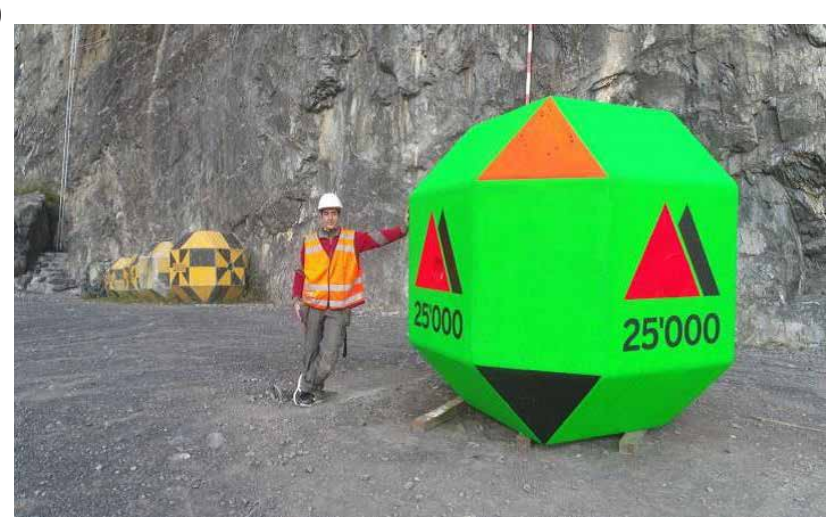

falling at a speed of $90 \mathrm{~km} / \mathrm{h}(25 \mathrm{~m} / \mathrm{s})$ onto a RX-300 barrier mesh with a ring structure (Figure 9 ).

In 2011, similar strength tests were carried out, in which the striking element was a concrete block with a mass of $16,000 \mathrm{~kg}$ (16 tons), dropped from a height of $32 \mathrm{~m}$ at a final speed of $90 \mathrm{~km} / \mathrm{h}$. In addition, the company tested strength and deformability of steel meshes protecting against rock fragments, by dropping on them concrete blocks of 20 and 25 tons, falling vertically from a height of $43 \mathrm{~m}$, achieving speed of $103 \mathrm{~km} / \mathrm{h}(28.61 \mathrm{~m} / \mathrm{s})$. Dynamic load-bearing capacity of the meshes was 10,000 kJ (Figure 10) [13-16].

\subsection{Methodology for strength evaluation of flat, including openwork textile products}

In case of openwork textile products, the methodology of conducting strength tests is similar to tests performed for steel meshes. The only difference is the type of raw material from which the samples are made. A deflection test of a mesh made of basalt fibers, used as a composite in the mining industry, can be taken as an example. The test is conducted in a similar way as in case of the "box test" method. It is carried out in accordance with the requirements included in PN-G-15050: 1996 standardLining for mining excavations. The meshes selected for testing have standard dimensions of $50 \mathrm{~cm} \times 50 \mathrm{~cm}$, and the frame is $1 \mathrm{~m} \times 1 \mathrm{~m}$. Total deflection of the mesh depends on how rigidly it is fastened in the machine holders (Figure 11).

Another method for evaluating multidirectional strength of openwork materials is to assess the durability of mesh safety products used in elevated works.

Depending on the type of mesh and the conditions of use, the product must meet the appropriate requirements concerning mechanical properties, including dynamic load-bearing capacity and strength.

The meshes preventing people and objects against falling down from a height are subjected to strength tests in a similar way as Geobrugg steel meshes. During the tests some objects of various mass are dropped down onto the samples from a b)

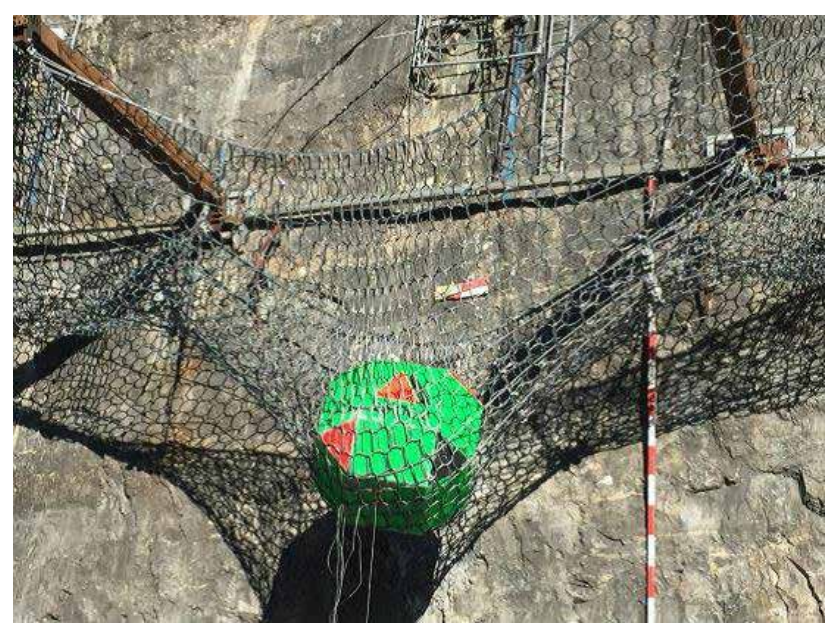

Figure 10. Vertical impact test against Geobrugg barrier mesh: (a) concrete block weighting 25 tons, (b) deflection of steel barrier mesh [13, 17, 18]. 


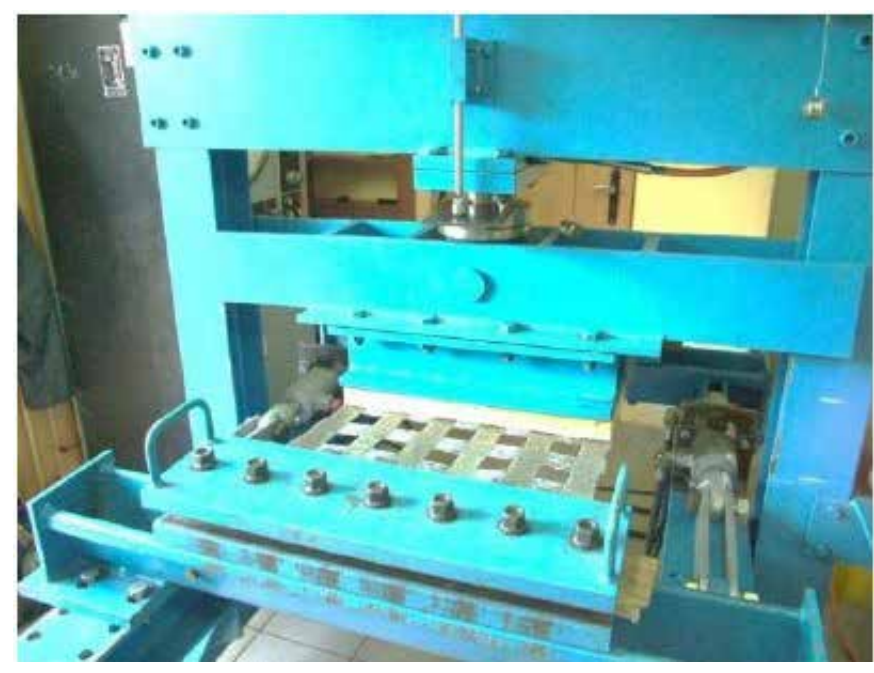

Figure 11. Testing meshes made of basalt fiber called POLLUX2 using box load [19].

a)

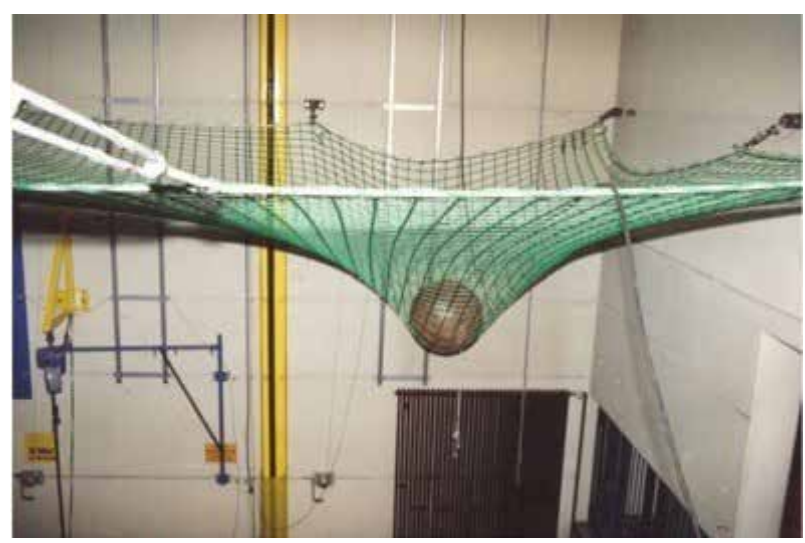

b)

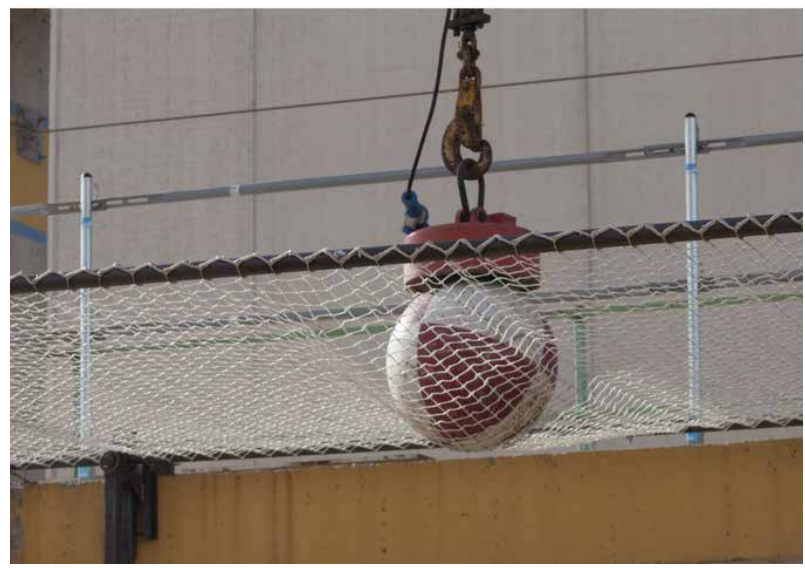

Figure 12. Strength tests of safety meshes: (a) free fall of the ball, (b) ball dropped with a lifting cable [22, 23].

certain prescribed height [20, 21] (Figure 12). The main purpose of these tests is to measure the mesh tear strength and its maximum deflection.

In addition, tearing strength tests carried out for safety meshes include their individual components, starting from the assessment of mechanical parameters of the threads forming the stitches, to the evaluation of individual eyelets of the openwork mesh and the entire surface of the product (Figure 13).
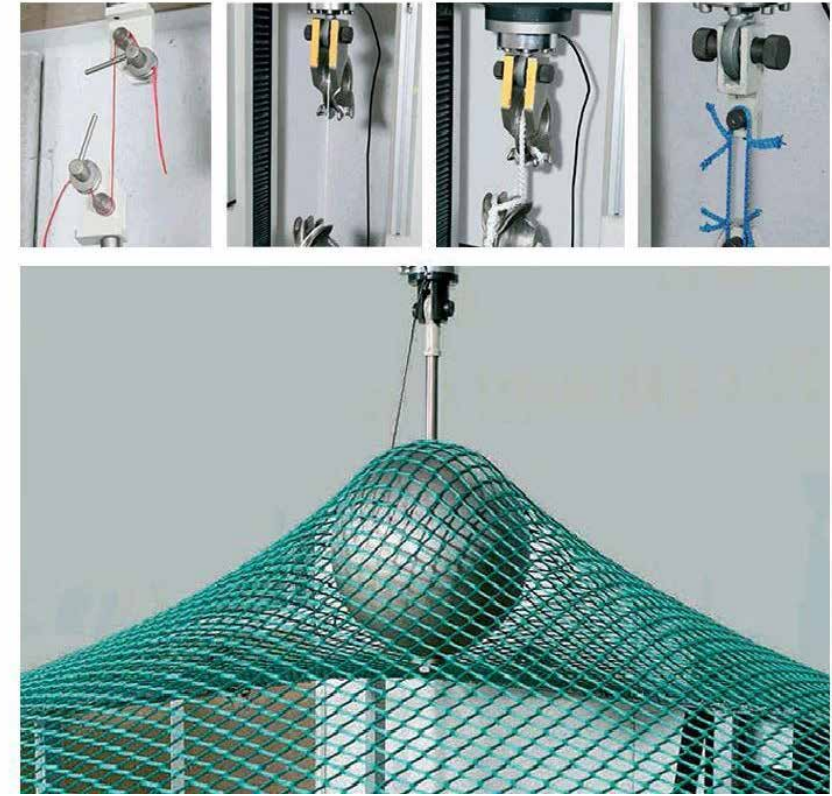

Figure 13. Testing of security systems, based on research conducted at ALGO SYSTEM company producing meshes and ropes [22].

a)

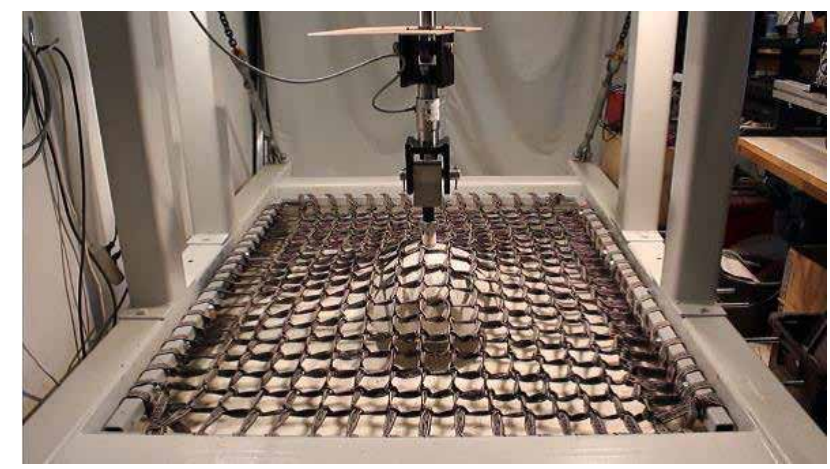

b)

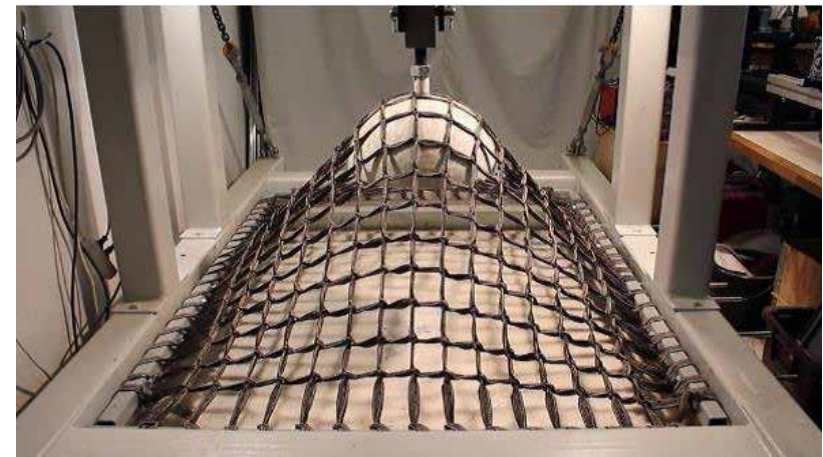

Figure 14. Subsequent phases of bursting protective mesh during push out test [24].

The next strength test for textile mesh products is the push-out test [23]. The test is conducted in such a way that the tested model with appropriate dimensions is placed on a frame and is then subjected to pushing from the underneath using a ball placed under the mesh (Figure 14).

The biaxial method is used for testing multidirectional strength of openwork textile products. This method consists in evaluating the mesh strength in two perpendicular directions: vertical and horizontal, with tensile force applied simultaneously. The method is based on different types of measurement 


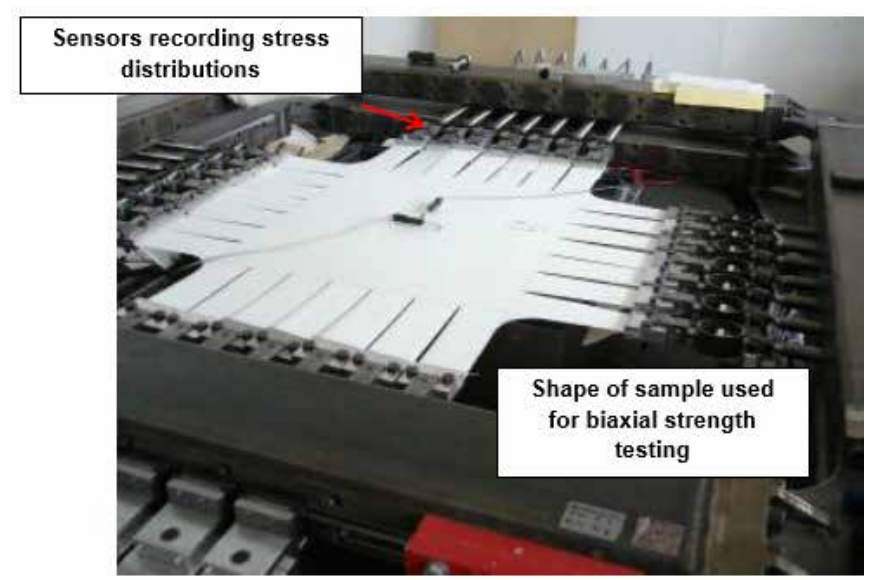

Figure 15. Biaxial strength testing machine, at Taiwan Textile Institute (TTRI) [25].

procedures, including: bursting test and cylinder test. It should be emphasized that the testing methods mentioned above are mainly used for woven materials. The tested samples are cut out in the shape of a "cross," which enables appropriate recording of stress distribution in a direction perpendicular to the load applied by the stretching arm. There are two types of machines for testing biaxial strength of textile products. One of them is a tensile testing machine located at the Taiwan Textile Institute (TTRI), which was designed by the Blum Laboratory in Germany [10-12]. The machine consists of a square frame on which four separate blocks are located. Each block is equipped with seven controllers for stretching the tested sample (Figure 15).

The controllers are fixed in such a way so as to allow motion transverse to the applied testing force. The sample in the shape of a "cross" is cut out in an orthogonal manner with a central square of $700 \mathrm{~mm} \times 700 \mathrm{~mm}$, arm length of $260 \mathrm{~mm}$, and with a corner radius of $80 \mathrm{~mm}$. The stress distribution is measured by sensors placed on each of the sample arms.

Another device for biaxial testing is the machine used at the University of Newcastle [25, 26] in which upper frame can move in two directions enabling the loads to be adjusted to the directions along which the tests are conducted. The way the frame moves also allows the so-called "floating" and is based on the concept developed by a British scientist who dealt with membrane constructions Architen-Landrell (Chepstow, United Kingdom) [23, 24]. An additional benefit from using the so-called "floating" frame is that the load can be applied by single device to each of the tested axes with the same or different force value. The sample in the shape similar to a "cross" has in its central part a square of $300 \mathrm{~mm} \times 300 \mathrm{~mm}$ and its arms of $150 \mathrm{~mm}$ are divided into ten sections, fixed respectively on each of the four sides of the device (Figure 16). The method of cutting out the sample differs from the previously described example in that the sample in the shape of a "cross" is cut out in such a way that the arms of the "cross" overlap with the direction of the warp and weft. The cutting angle of the sample along the warp is usually from $0^{\circ}$ to $5^{\circ}$. The applied load is controlled by a hydraulic cylinder for each axis, and the resulting stresses are measured with two $100 \mathrm{~mm}$ long linear transducers (Figure 17) [25-27].

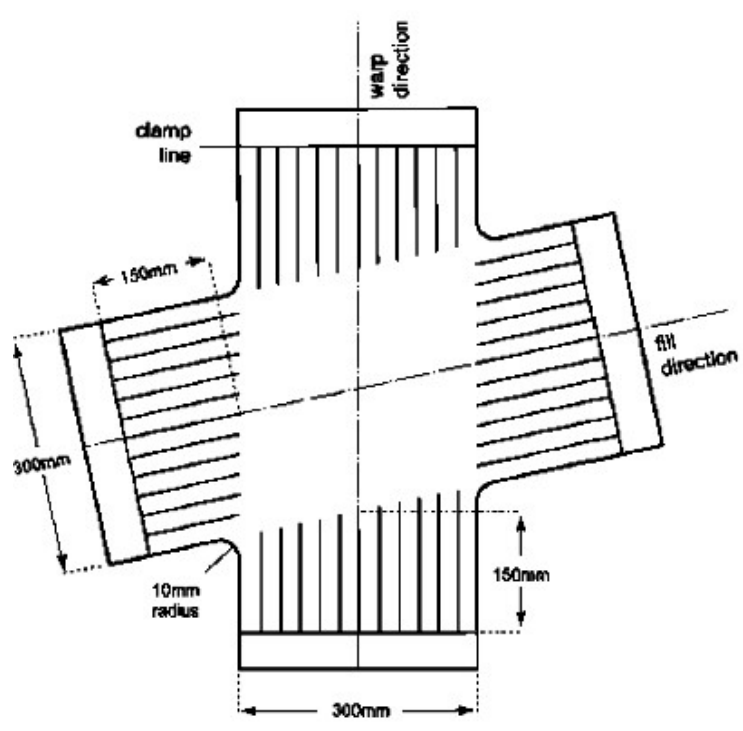

Figure 16. Shape of sample used for biaxial strength testing (Newcastle University) [24].

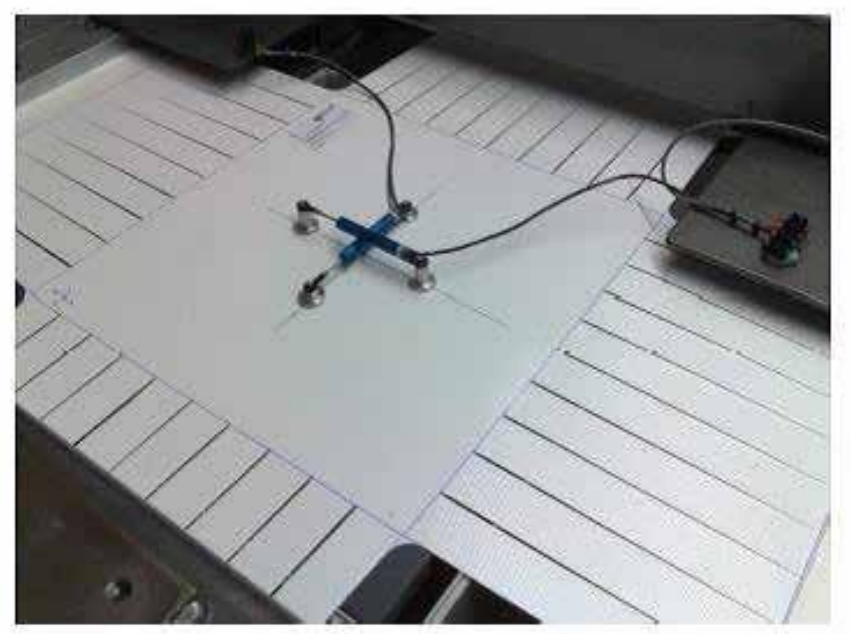

Figure 17. Real shape of sample used for biaxial strength testing (Newcastle University) [27].

Literature analysis indicates various solutions and research methods in terms of measuring static and dynamic strength of mesh objects made of steel or textile raw materials. The specificity of measuring methods refers to the actual conditions of use of the meshes, both in the field of mining and construction protection or in road engineering safety. Generally, metrological or practical tests are aimed at determining the limit values of the mesh breaking forces and the susceptibility of the mesh deformations to force excitations. In addition to one item cited, related to theoretical numerical analysis of the distribution of forces (reduced stress) in fastening elements and steel mesh bars, the other measurement methods quoted in the literature do not take into account a more detailed, in-depth experimental analysis of the mesh strength characteristics. The main goal of developing a new method for identifying the mechanical properties of meshes was to conduct an experimental analysis and strength of stresses and deformations, both in the fixing nodes and in the mesh surface, taking into account the features of their construction and the method of forcing impact energy. 


\section{Test stand for the analysis of dynamic stress distribution in knitted barrier meshes}

The literature analysis of the methods for strength evaluation shows that they mainly concentrate on the measurement of uni- or bi-directional resistance and deformation amount $\Delta u$ in static and dynamic aspect. A review of existing research methods has enriched the authors with valuable knowledge in the area of tools and measurement techniques, and was also useful in formulating the assumptions of the new instrumental methodology for analyzing textile mesh strength. The important guidelines adopted for the new research method was to define the following assumptions:

- the geometrical form of the mesh and the multidirectionality of measured forces (stresses) and deformations will depend on the actual shape of the object;

- the number and distribution of stress measuring elements correlates with the number and distribution of boundary mesh nodes;

- the shape and dimension of the tested object may be different and they determine the shape and dimensions of the frame on which the force measurement sensors are mounted. In the version presented in the publication, the mesh has a square shape of $0.7 \mathrm{~m} \times 0.7 \mathrm{~m}$;

- measurement of the mechanical properties of the meshes can be carried out in both static and dynamic terms;

- the object forcing deformation is a body of a given shape, dimensions and mass. In the tests of the analyzed meshes, a dropping ball was used from a height of $1 \mathrm{~m}$ or $2 \mathrm{~m}$;

- the deformation force direction can be varied as to the point of application in the mesh surface and direction. In tests, the excitation is directed centrally to the mesh surface in a perpendicular direction;

- force and deformation values are measured in real time in an on-line system;
- force measurement is carried out by indirect deformation method of elastic strings using strain gauge sensor technology, while deformation measurement is measured by 3D optical method of mesh deflection registration.

The concept of building a measuring stand for analyzing the distribution of dynamic stresses in knitted barrier meshes has been divided into two stages. The first one is the development of the test stand from the viewpoint of mechanics, and the other is elaborating the electronic solutions, related to the system of strain gauges for stress measuring.

In the mechanical part, several variants of the construction of the experimental stand were considered differing in frame geometry and the arrangement of the holders on which the strain gauges are located, which will enable multidirectional measurement of forces and deformations distribution in the examined meshes. Figure 18 presents three considered variants of test stand differing in the frame shape. The arrows show the direction of testing longitudinal forces.

The models were made in the Autodesk Inventor software environment. The variant chosen for measurement purposes was the one with square frame and holders with sensors placed around. The variant with a tetragonal frame was selected due to the actual shape of road barriers stretched on a supporting frame. Analyzing force distribution, the selected frame construction seems the most convenient in terms of stress measurement efficiency and the ease of measurement in two directions of the axes.

Four different variants of the measuring stand with the selected frame shape were developed by considering different arrangements of the holders and the method of mesh fastening. The variants possessed oblique, horizontal, L-shaped and vertical systems of strings, and the mesh was fixed using spiral shaped hooks (strings). The last project, compared to the three solutions mentioned above, represents in a simplified way the approach to the subject of testing multidirectional dynamic stresses in mesh structures. It was assumed that the eyelets will be fixed to the frame with the help of hooks with the spiral shape (Figure 19).
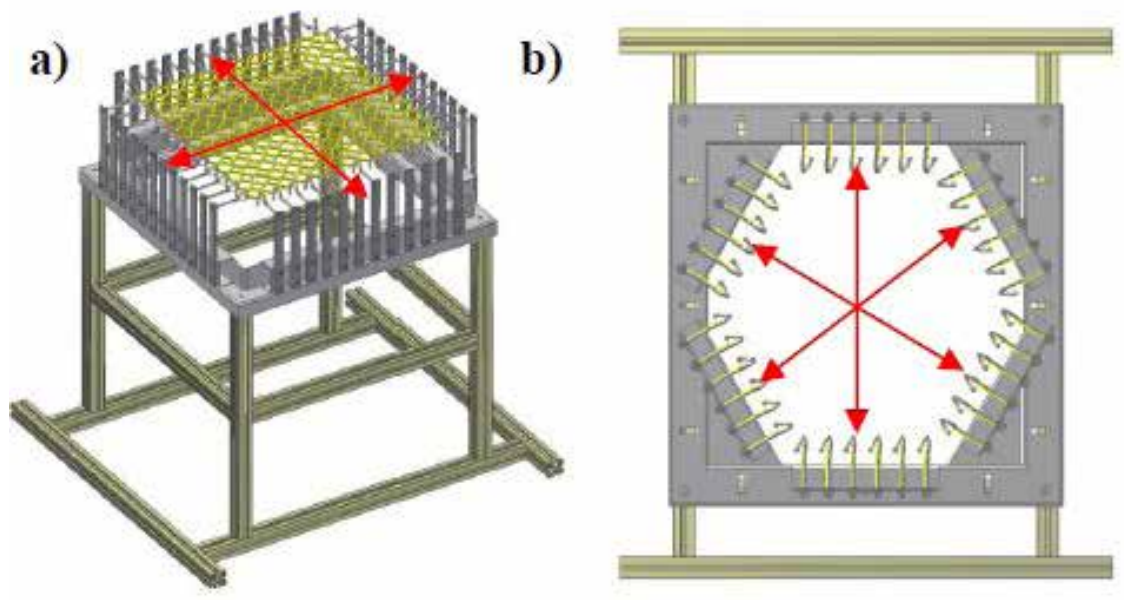

c)

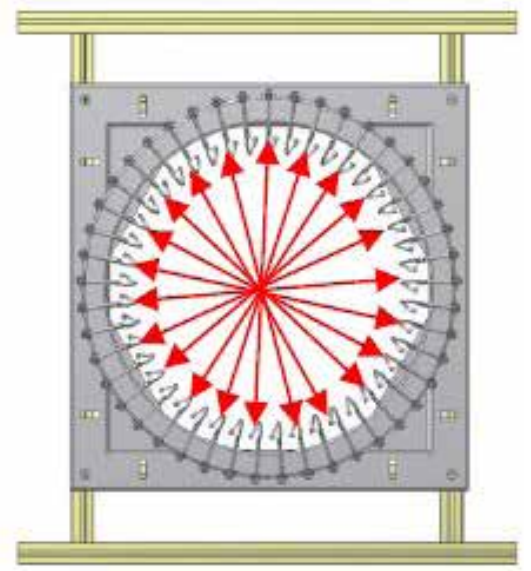

Figure 18. Measuring stand for the analysis of multidirectional dynamic stress distribution in knitted barrier meshes with frame in the shape of: (a) square, (b) hexagon, (c) circle. 
The applied hooks (strings) were supposed to facilitate the process of fastening the tested meshes in the frame. It is assumed that the vertical strings equipped with measuring elements (strain gauges) will bend toward the mesh under the influence of the object simulating the impact [27].

a)

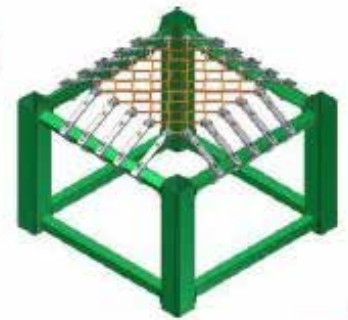

c)

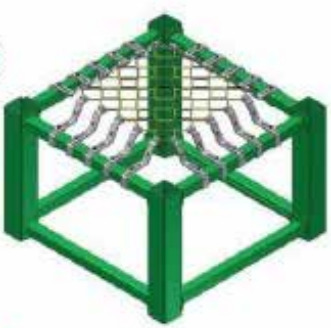

b)

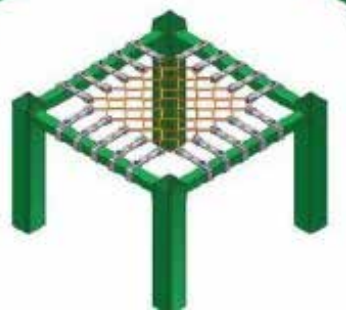

d)

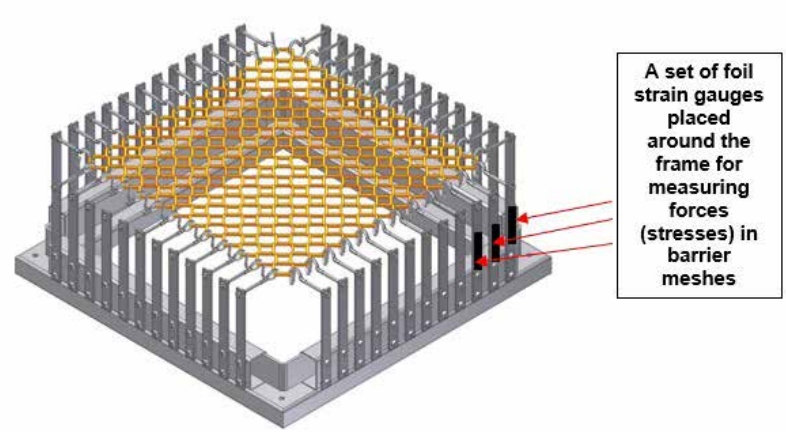

Figure 19. Stand for analysis of dynamic stress distribution in knitted barrier meshes with:(a) oblique, (b) horizontal, (c) L-shaped holder systems: (d) vertical string system with spiral shaped hooks for mesh fixing.

a)

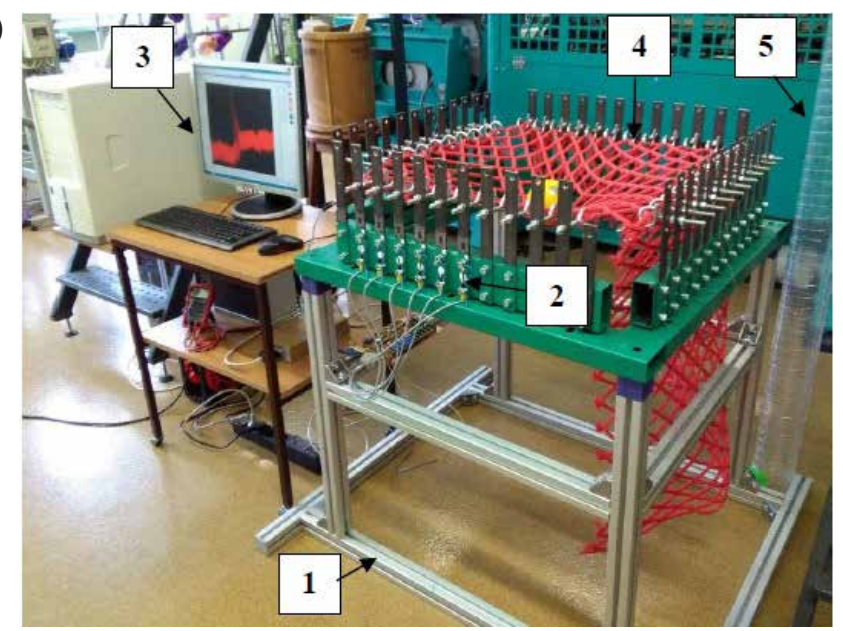

Figure 20 shows the actual view of the measuring stand with a system of holders equipped with strain gauges and strings in the form of spiral hooks for mesh fastening. The basic element of the test stand is the frame, whose upper horizontal beams allow spreading of the mesh with the use of strings (spiral hooks). The device is equipped with 48 holders, located on each side around the entire frame, and equipped with strain gauges. Due to the symmetrical stress and deformations distribution observed in simulation tests, when the mesh was dynamically loaded with a ball in its central point, it was decided to apply 12 holders located in one of the corners of the measuring frame in the final version, that is, 6 holders equipped with measuring elements (strain gauges) on each of the two sides.

Depending on the adopted geometry of the a-jour structure, each of the holders was equipped with hooks for fastening mesh knots, which ensured appropriate pre-tension. The measuring frame is $80 \mathrm{~cm} \times 80 \mathrm{~cm}$, and the mesh sample has constant dimensions of $0.7 \mathrm{~m} \times 0.7 \mathrm{~m}$, regardless of the shape of the a-jour structure. The strings are attached to the beam, which is treated as a slidable element.

There are 4 beams in the frame, one on each side, and each beam has 24 holes spaced $5 \mathrm{~cm}$ from each other, to which the holders with hooks are fastened. It was assumed that the striking object is a ball with a diameter of $10 \mathrm{~cm}$ and a mass of $5 \mathrm{~kg}$. The ball dropping path from a certain height is properly directed thanks to a set of guiding tubes. The length of a single section of the tube is $2,000 \mathrm{~mm}$, its internal diameter equals $104 \mathrm{~mm}$, and wall thickness $3 \mathrm{~mm}$. The height from which the ball is dropped is in the range of $0 \mathrm{~m}-6 \mathrm{~m}$, changed by $0.5 \mathrm{~m}$ every time. This is possible thanks to the use of an appropriate number of tube sections and an additional latch, setting the zero point of the ball. In the electronic part of the test, related to the strain gauges system for measuring longitudinal forces, including stresses, TFs-10/350 foil strain gauges with resistance of $\Omega=350 \pm 0.2 \%$ were selected. The strain gauges were stuck vertically on the holders. LL 7-4, 5-1.5 solder bars was used to connect the ends of the strain gauges to the wires [28].

The measuring system included the following elements: $10 \mathrm{~K}$ horizontal single-turn potentiometer, 15 turn potentiometer $19 \mathrm{~mm} 500 \mathrm{R} 0.75 \mathrm{~W}, 15$ turn potentiometer $19 \mathrm{~mm} 500 \mathrm{k}$ $0.75 \mathrm{~W}$, adjustable voltage stabilizer 2.8-36 $\mathrm{V} 2 \mathrm{~A}$, 1-channel operational amplifier $600 \mathrm{kHz}$ DIP8, and a prototype board $100 \mathrm{~mm} \times 160 \mathrm{~mm}$ with DIN connector.

b)

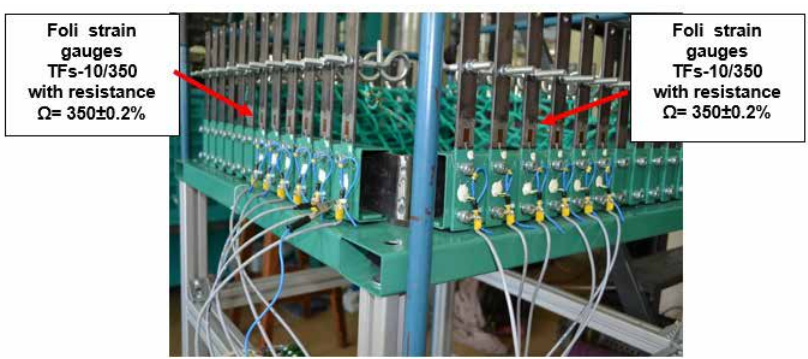

Figure 20. Real view of measuring stand for the analysis of multidirectional dynamic stress distribution in knitted barrier meshes: (a) real view of measuring stand: (1) stand footing, (2) square-shaped frame, with measuring holders equipped which strain gauges and strings in the form of spiral hooks for mesh fastening, (3) computer with program for archiving measurement results, (4) barrier mesh-verification material, and (5) guiding tube ensuring correct dropping path of object hitting object (ball) and (b) arrangement of strain gauges. 

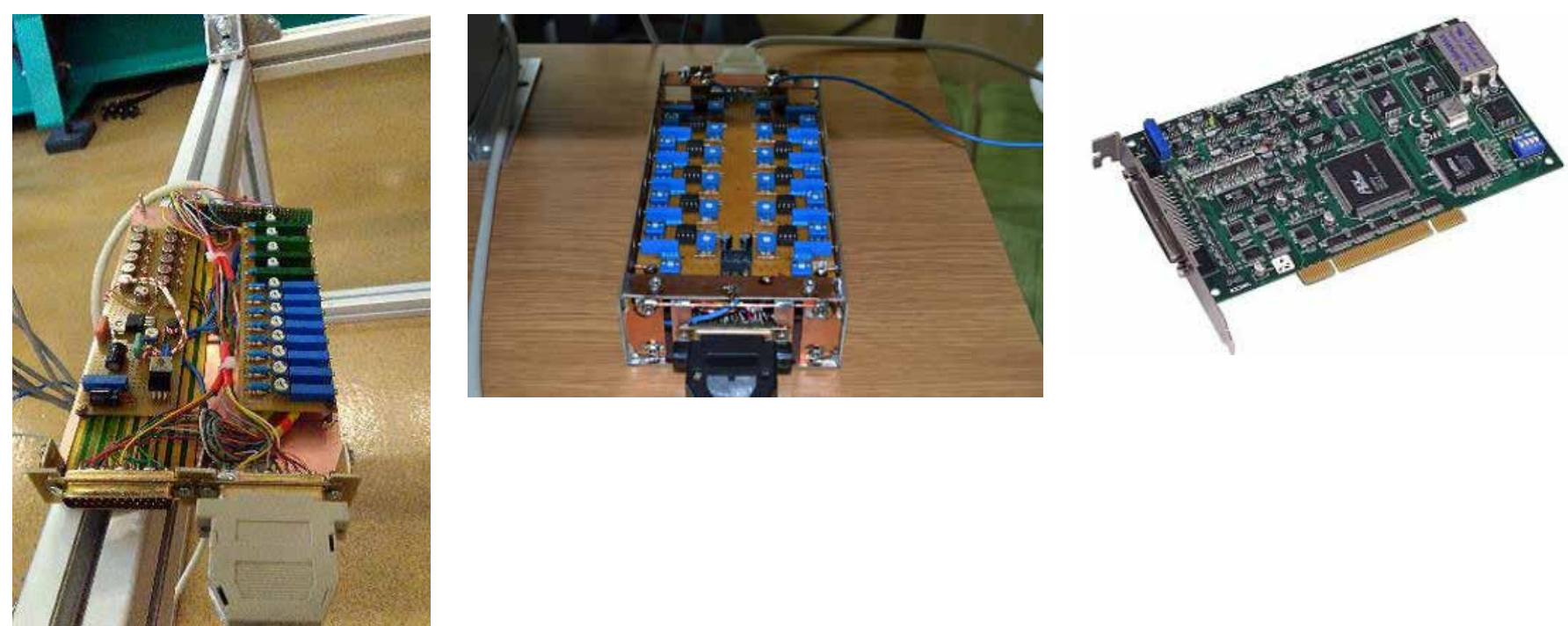

Figure 21. Measuring system on a prototype board $100 \mathrm{~mm} \times 160 \mathrm{~mm}$ with DIN connector and card for archiving data used in the measurement and counting system.

The electronic components of the device were connected together to create a circuit for measuring the distribution of forces in the tested barrier meshes. Additionally, the electronic system was closed in a housing to minimize the phenomenon of undesirable noises or signal interference (Figure 21).

The next component of the electronic measuring system was the card for data acquisition PCl-b1741U-AE, used to collect and record the obtained measurement results. The card has a programmable timer (82C54), containing three 16-bit meters $[29,30]$. The first one allows to count the pulses from the input channel with a frequency up to $10 \mathrm{MHz}$, and can be used freely, while the other two form a cascade 32-bit A/C converter trigger system. The signal is converted from analog to digital in the considered system.

The analog key receives signals from the extensometer amplifier and then, they are redirected to the computer card, where the analog signal is converted to digital. The system is equipped with a non-impulse $12 \mathrm{~V}$ transformer power supply, rectifiers, and filters with an RC system to obtain the smallest system noises at the output. The set of bridges and extensometer operational amplifiers has a gain powered by symmetrical voltage $\pm 15 \mathrm{~V}$. Each of the bridges has a separate power supply. Some mass was added to the measuring system for its proper operation. The bridges do not interact with each, other due to the use of a separate power supply.

\section{Simulation tests of forces distribution in the fixing knots of barrier meshes}

3.1. Numerical analysis of stress and deformation distribution in strings, knots and elements of the mesh structure

The purpose of the numerical calculations was to determine the repeatability of stresses and deformations occurring on the perimeter of the tested meshes. The results of this study had a significant impact on the construction of the measuring stand, including the number of sensors measuring stresses in the mesh models. In the measuring frame, four strings $4 \times 12$ fastening the grid nodes were arranged on the perimeter of the sides of the square in the constructed test stand. For homogeneous meshes, that are with a-jours in the form of symmetrical geometric figures (square, rhombus, circle, polygon) with repetitive dimensions and evenly distributed in the mesh surface, it can be expected that the distribution of forces and deformations will be symmetrical along two perpendiculars to the side lines of the symmetry axis mesh. This assumption, of course, is correct when forced by a central object in the mesh surface in the form of a ball falling freely from a certain height. In this case, a sufficient area of the mesh study is its fourth part (a 1/4 cut out with lines of symmetry). To identify this area is needed $1 / 4$ of the number of all strings (handles) equipped with measuring sensors. This significantly simplifies the methodology for measuring forces and deformations. In order to prove the presented thesis, model analysis (numerical SEM) is necessary to determine the distribution of forces in the mesh strings (symmetrical or asymmetrical distribution). This kind of approach to the planned experiment is necessary, not to be guided by intuition, but by confirmed facts about the distribution of mechanical properties of the mesh.

Numerical tests were conducted with static approach, by applying a load force directed vertically toward the z-axis, in the central part of the mesh. The simulations were carried out for two mesh models with diamond and square-shaped a-jour structure. For the calculations it was assumed that the geometric models were $0.7 \mathrm{~m} \times 0.7 \mathrm{~m}$, and the eyelets of one openwork fabric were $50 \mathrm{~mm} \times 50 \mathrm{~mm}$ and of the other $45 \mathrm{~mm}$ x $45 \mathrm{~mm}$. The considered variants were characterized by structural parameters typical for real meshes, which were then used as verification material in the experimental part of the work (Section 4). The meshes had the same raw material composition and structure of constituent stitches. They differed in some structural parameters such as wale and weft density, eyelet shape ratio $\mathrm{C}$, weight and Young's modulus. The models demonstrated parameters of real raw material in the form of polypropylene yarn with density of $910 \mathrm{kgm}^{-3}$, Poisson ratio 0.30 , and Young's modulus for variant S2-10.50 MPa and for variant S3-8.67 MPa. The simulation studies focused mainly 
a)

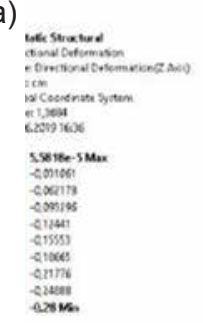

c)

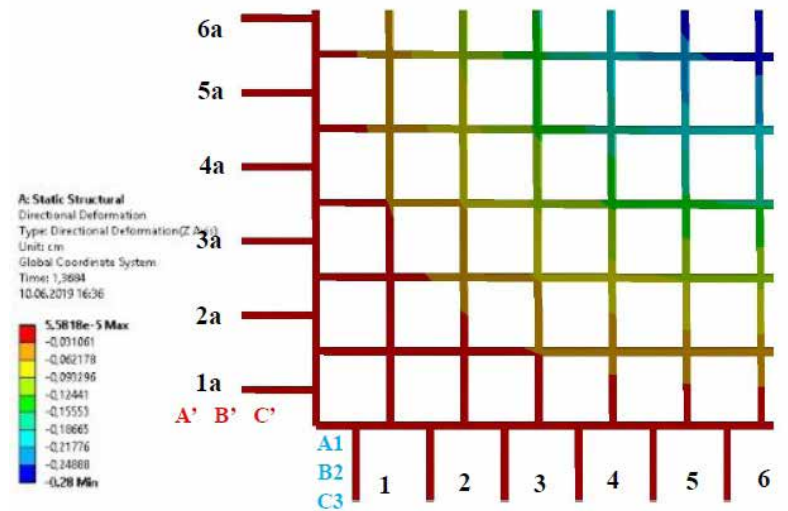

b)

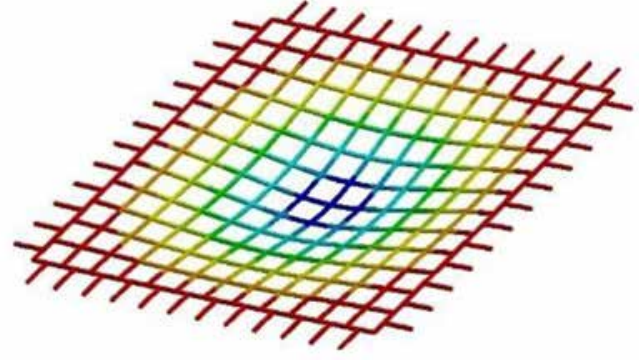

itatic Structural al Bending Momen le: Total Bending Moment (Unweraged) tin-m 1e: 1 .201917:08

$7,3206 \mathrm{Max}$ 6,507 5,6938 4,8004 4,067 3,2536 2,4402

1,6268

0,8134 2.7011e-6 Min

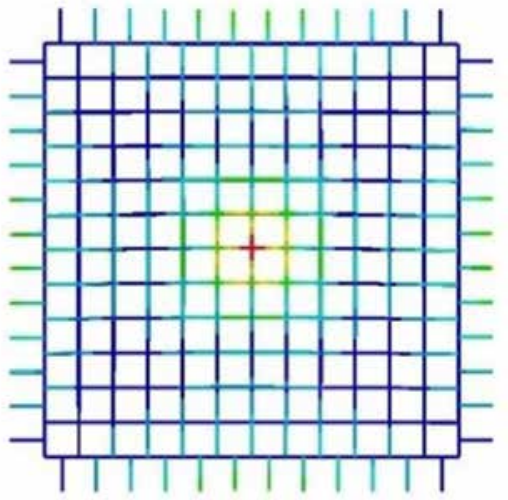

Figure 22. Analysis of deformations distribution in mesh with square-shaped a-jour structure (variant S2-K1): (a) distribution of mesh deformations in the direction of z-axis for variant $\mathrm{K} 1$, (b) bending moment recorded in mesh elements, (c) symmetrical distribution of absolute deformations in strings and knots.

Table 1. Deformation values in mesh strings for variant 2-K1

\begin{tabular}{|c|c|c|c|c|c|}
\hline $\begin{array}{l}\text { Bottom } \\
\text { strings }\end{array}$ & $\begin{array}{l}\text { Absolute deformations in } \\
\text { individual string pairs, } \mathrm{cm}\end{array}$ & $\begin{array}{l}\text { Side } \\
\text { strings }\end{array}$ & $\begin{array}{l}\text { Bottom } \\
\text { strings }\end{array}$ & $\begin{array}{l}\text { Absolute deformations in } \\
\text { individual string pairs, } \mathrm{cm}\end{array}$ & Side strings \\
\hline 1 & 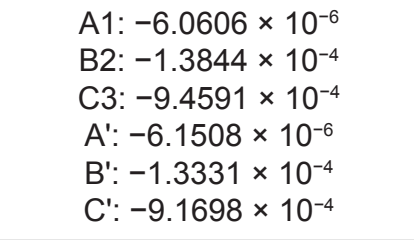 & $1 a$ & 4 & $\begin{array}{l}\text { A1: }-1.5579 \times 10^{-4} \\
\text { B2: }-1.5658 \times 10^{-3} \\
\text { C3: }-8.3644 \times 10^{-3} \\
\text { A': }^{\prime}-1.2829 \times 10^{-4} \\
\text { B': }^{\prime}-1.7095 \times 10^{-3} \\
\text { C': }^{\prime}-8.2965 \times 10^{-3}\end{array}$ & $4 a$ \\
\hline 2 & 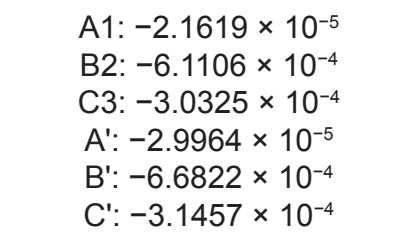 & $2 a$ & 5 & 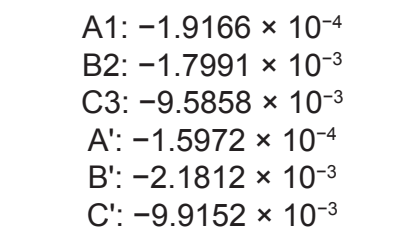 & $5 a$ \\
\hline 3 & 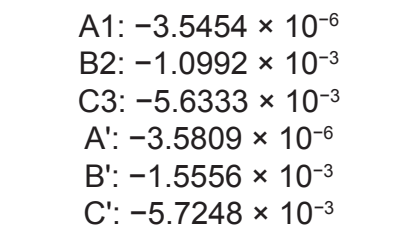 & $3 a$ & 6 & $\begin{array}{l}\text { A1: }-6.8221 \times 10^{-6} \\
\text { B2: }-1.7611 \times 10^{-2} \\
\text { C3: }-2.2512 \times 10^{-2} \\
\text { A': }^{\prime}-6.5488 \times 10^{-6} \\
\text { B }^{\prime}:-1.1279 \times 10^{-2} \\
C^{\prime}:-2.1334 \times 10^{-2}\end{array}$ & $6 a$ \\
\hline
\end{tabular}

on the analysis of stress distribution: in the strings, fixing knots and in the mesh surface.

Meshes with square a-jour structure were analyzed first (variant S2-K1). Figure 22a shows the deformation of the mesh which was edge-fastened on 48 strings. The mesh was loaded with a force of 1,000 $\mathrm{N}$ directed vertically toward the z-axis. Figure $22 \mathrm{~b}$ shows symmetrical distribution of the bending moment values in the elements of the mesh construction. The analysis of deformation values in the individual string pairs showed their symmetrical distribution in strings, knots and in the entire mesh.
Figure 22c shows an example of the considered deformation distribution in $1 / 4$ of the mesh surface. It shows the symmetrical arrangement the recorded values. Deformations distribution in individual string pairs is presented in Table 1.

The places of deformations and forces measurements in the strings were marked with blue, in the following way: A1-place next to the rigid fastening of the mesh, B2-place in the middle of the string, C3-place next to the knot. The calculations in the system of strings located on the adjacent side of the mesh 

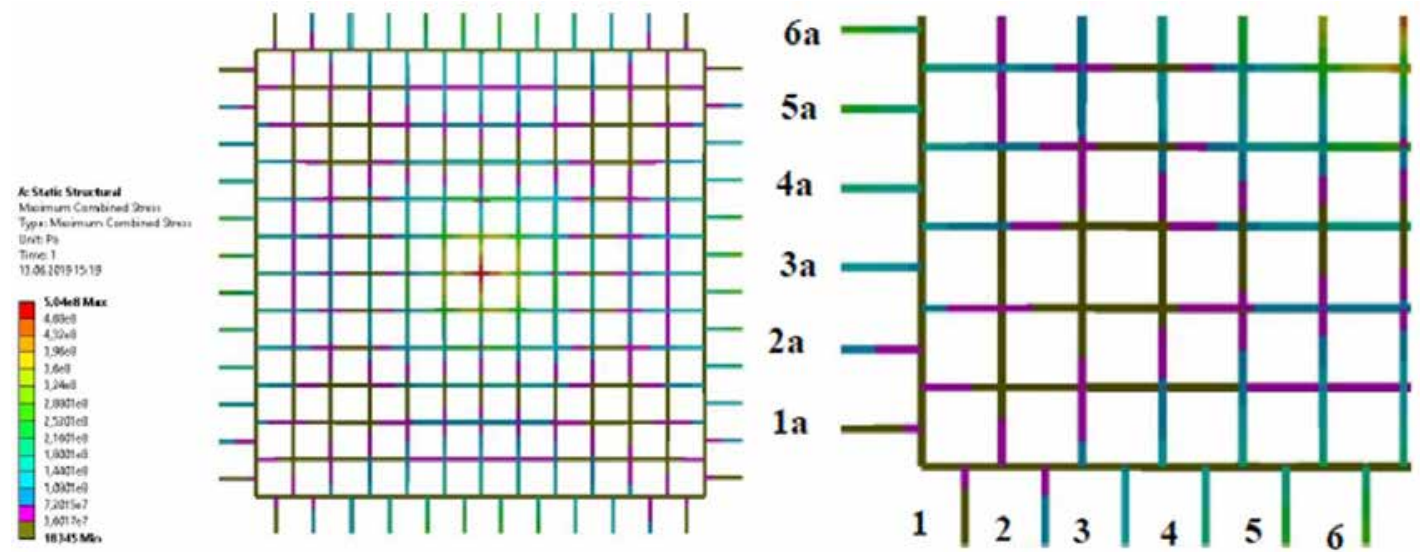

Figure 23. Analysis of reduced stresses distribution in mesh with square-shaped a-jour structure (variant S2-K1) (symmetrical distribution of reduced stresses in strings and mesh.)

Table 2. Reduced stress values in mesh strings for variant S2-K1

\begin{tabular}{|c|c|c|c|c|c|}
\hline Bottom strings & $\begin{array}{l}\text { Reduced stresses in } \\
\text { individual string pairs, MPa }\end{array}$ & $\begin{array}{l}\text { Side } \\
\text { strings }\end{array}$ & $\begin{array}{l}\text { Bottom } \\
\text { strings }\end{array}$ & $\begin{array}{l}\text { Reduced stresses in } \\
\text { individual string pairs, MPa }\end{array}$ & $\begin{array}{l}\text { Side } \\
\text { strings }\end{array}$ \\
\hline 1 & $\begin{array}{l}\text { A1: } 14.371 \\
\text { B2: } 23.782 \\
\text { C3: } 23.899 \\
A^{\prime}: 11.515 \\
B^{\prime}: 20.555 \\
C^{\prime}: 22.314\end{array}$ & $1 a$ & 4 & 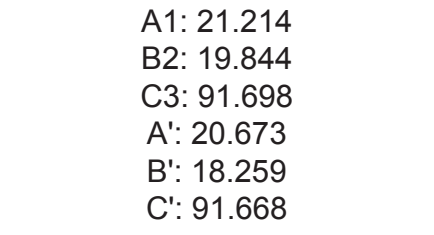 & $4 a$ \\
\hline 2 & 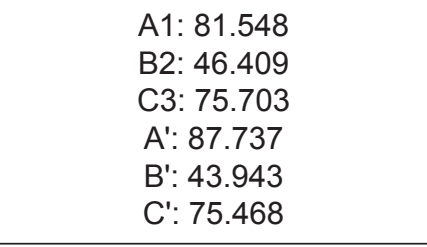 & $2 a$ & 5 & $\begin{array}{l}\text { A1: } 26.321 \\
\text { B2: } 22.555 \\
\text { C3: } 20.673 \\
A^{\prime}: 20.673 \\
B^{\prime}: 22.774 \\
C^{\prime}: 22.261\end{array}$ & $5 a$ \\
\hline 3 & $\begin{array}{l}\text { A1: } 14.953 \\
\text { B2: } 13.473 \\
\text { C3: } 73.495 \\
A^{\prime}: 14.435 \\
B^{\prime}: 18.259 \\
C^{\prime}: 72.735\end{array}$ & $3 a$ & 6 & 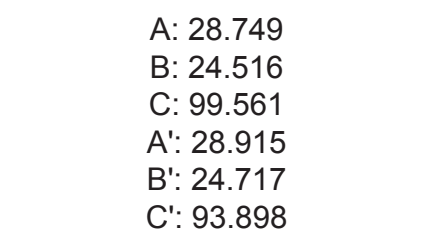 & $6 a$ \\
\hline
\end{tabular}

were made in a similar way, and marked successively: $A^{\prime}, B^{\prime}$, $C^{\prime}$.

An analysis of reduced stress distribution in the strings and in the mesh was also carried out, irrespective of the values obtained in the mesh knots. Figure 23 illustrates the configuration of these values and their symmetrical distribution in the considered mesh elements. Table 2 also presents symmetrical distribution of stresses in individual string pairs.

Identical program of numerical tests was carried out for meshes S1-R1 (diamond-shaped a-jour structure) and two additional mesh variants S3-K2 and S3-R3, differing from the previous ones with structural parameters and longitudinal rigidity of the mesh arms.

The performed numerical analysis of stresses and deformations in the fastening strings, knots and in the mesh surface proves that they are distributed symmetrically, along two axes perpendicular to the sides of the mesh. Logically, such an answer could be expected taking into account the "regular and homogeneous" study material, which were square meshes with square and diamond-shaped a-jour structures, and strings fastening the meshes to the frame evenly arranged around the mesh perimeter. As a result of the tests, some assumptions were made regarding the construction of a stand for measuring multi-axial dynamic loads in knitted barrier meshes. It was assumed that for homogeneous square mesh structures, "representative" measurements can be performed in 1/4 of the mesh with 12 strain gauges, and a total number of 48 points in which the mesh is fastened to the measuring frame.

\section{Experimental research as a validation of numerical analysis of dynamic stress distribution in the surface of barrier meshes}

Experimental studies were carried out on the measuring stand described in Section 4.2. The purpose of the research was a qualitative analysis of stress distribution in the mesh fastening strings. 


\subsection{Research material}

In the first stage of the research, three mesh variants were designed and manufactured, two of which were identical as variants S2 and S3 used in the theoretical analysis carried out in the previous section.

The first variant was a mesh made of interlacing cords (variant S1), forming a square-shaped a-jour structure $5 \mathrm{~cm} \times 5 \mathrm{~cm}$. The cords with a diameter of $\phi=4.46 \mathrm{~mm}$ were made by knitting technology, using plain stiches. The raw material used for the stitches was polypropylene and the core was made of a yarn in the form of aramid roving Kevlar 49.
The second tested material was a mesh with diamondshaped a-jour structure (variant S2), consisting of tricot and velvet stitches, with eyelet size of $50 \mathrm{~mm} \times 50 \mathrm{~mm}$, made of polypropylene with knot thickness of $4.5 \mathrm{~mm}$.

The third variant was a mesh with diamond-shaped a-jour structure (variant 3), consisting of tricot and velvet stitches, with eyelet size of $45 \mathrm{~mm} \times 45 \mathrm{~mm}$, made of polypropylene. Mesh parameters together with stitches structure are shown in Table 3.

Table 3. Mesh structure and parameters

\begin{tabular}{|c|c|c|c|}
\hline Mesh variant & Variant S1 & Variant S2 & Variant S3 \\
\hline \multicolumn{4}{|l|}{ Mesh photographs } \\
\hline $\begin{array}{l}\text { Stitch type with pattern chain } \\
\text { record }\end{array}$ & Plain & $\begin{array}{c}\text { Tricot I and velvet II } \\
\text { bar I: } 34 / 32 / \times 6 / 56 / 32 / \\
\text { x3/34/32/x6/10/34/x3// } \\
\text { bar II: } 32 / 34 / \times 6 / 10 / 34 / \\
\text { x3/32/34/x6/56/32/x3// }\end{array}$ & $\begin{array}{l}\text { Tricot I and velvet II } \\
\text { bar I: 34/32/x6/56/32/ } \\
\text { x3/34/32/x6/10/34/x3// } \\
\text { bar II: } 32 / 34 / \times 6 / 10 / 34 / \\
\text { x3/32/34/x6/56/32/x3/I }\end{array}$ \\
\hline Shape of a-jour structure & Square & Diamond/square & Diamond/square \\
\hline Eyelet dimensions, $\mathrm{mm}$ & $50 \mathrm{~mm}$ & $50 \mathrm{~mm}$ & $45 \mathrm{~mm}$ \\
\hline Raw material & $\begin{array}{l}\text { Polypropylene with linear } \\
\text { density } 310 \text { tex Kevlar } 49 \\
\text { with linear density } 710 \text { tex }\end{array}$ & $\begin{array}{l}\text { Polypropylene with linear } \\
\text { density } 175 \text { tex }\end{array}$ & $\begin{array}{c}\text { Polypropylene with linear } \\
\text { density } 270 \text { tex }\end{array}$ \\
\hline Mesh dimensions & $0.7 \mathrm{~m} \times 0.7 \mathrm{~m}$ & $0.7 \mathrm{~m} \times 0.7 \mathrm{~m}$ & $0.7 \mathrm{~m} \times 0.7 \mathrm{~m}$ \\
\hline $\begin{array}{l}\text { Stitch thickness in mesh } \\
\text { knot, } \mathrm{mm}\end{array}$ & $5 \mathrm{~mm}$ & $5 \mathrm{~mm}$ & $4.5 \mathrm{~mm}$ \\
\hline $\begin{array}{l}\text { Wale density number of } \\
\text { loops } / 100 \mathrm{~mm}\end{array}$ & 40 wales $/ 100 \mathrm{~mm}$ & 30 wales $/ 100 \mathrm{~mm}$ & 50 wales $/ 100 \mathrm{~mm}$ \\
\hline $\begin{array}{l}\text { Course density number of } \\
\text { loops } / 100 \mathrm{~mm}\end{array}$ & 45 courses $/ 100 \mathrm{~mm}$ & 24 courses $100 \mathrm{~mm}$ & 40 courses $/ 100 \mathrm{~mm}$ \\
\hline Wale width $\mathrm{A}, \mathrm{mm}$ & $2.5 \mathrm{~mm}$ & $3.3 \mathrm{~mm}$ & $2.0 \mathrm{~mm}$ \\
\hline Course height $\mathrm{B}, \mathrm{mm}$ & $2.2 \mathrm{~mm}$ & $4.17 \mathrm{~mm}$ & $2.5 \mathrm{~mm}$ \\
\hline Loop shape ratio $\mathrm{C}$ & 1.13 & 1.26 & 1.25 \\
\hline $\begin{array}{l}\text { Diameter of mesh cord cross } \\
\text { section } \phi, \mathrm{mm}\end{array}$ & $4.46 \mathrm{~mm}$ & $5.36 \mathrm{~mm}$ & $4.34 \mathrm{~mm}$ \\
\hline \multicolumn{4}{|c|}{ Strength parameters } \\
\hline Relative elongation \% & 15.12 & 85.4 & 91.9 \\
\hline Maximum breaking force, $\mathrm{N}$ & 965 & 1,566 & 821 \\
\hline Young's modulus, MPa & 40.87 & 10.52 & 8.67 \\
\hline Weight, $\mathrm{kg} / \mathrm{m}^{2}$ & 2.70 & 5.70 & 3.70 \\
\hline
\end{tabular}


a)

\begin{tabular}{|c|c|} 
Channel 1 & $\mathrm{y}=60.771 \mathrm{U}-8.7276$ \\
\hline Channel 2 & $\mathrm{y}=58.073 \mathrm{U}-1.0348$ \\
\hline Channel 3 & $\mathrm{y}=61.593 \mathrm{U}-6.3908$ \\
\hline Channel 4 & $\mathrm{y}=56.826 \mathrm{U}-2.5222$ \\
\hline Channel 5 & $\mathrm{y}=59.58 \mathrm{U}-11.543$ \\
\hline Channel 6 & $\mathrm{y}=60.245 \mathrm{U}-1.8935$ \\
\hline Channel 7 & $\mathrm{y}=57.917 \mathrm{U}-5.7344$ \\
\hline Channel 8 & $\mathrm{y}=61.292 \mathrm{U}-4.2391$ \\
\hline Channel 9 & $\mathrm{y}=47.378 \mathrm{U}-2,9054$ \\
\hline Channel 10 & $\mathrm{y}=53.198 \mathrm{U}-4.9469$ \\
\hline Channel 11 & $\mathrm{y}=56.808 \mathrm{U}-2.1969$ \\
\hline Channel 12 & $\mathrm{y}=54.142 \mathrm{U}-9.3051$ \\
\hline
\end{tabular}

b)

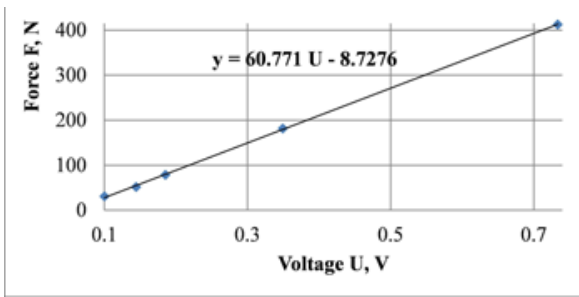

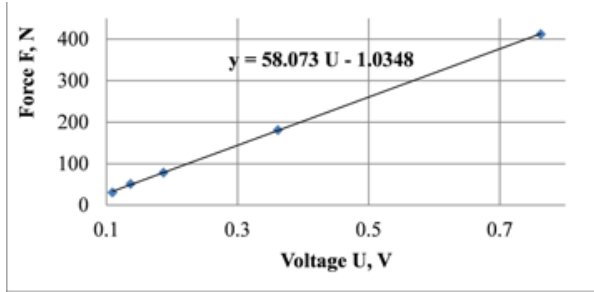

Figure 24. Calibration of measuring system: (a) calibration function equations, (b) examples of calibration charts for channels 1 and 2 with a load from $3.0 \mathrm{~kg}$ to $42.0 \mathrm{~kg}$.

a)

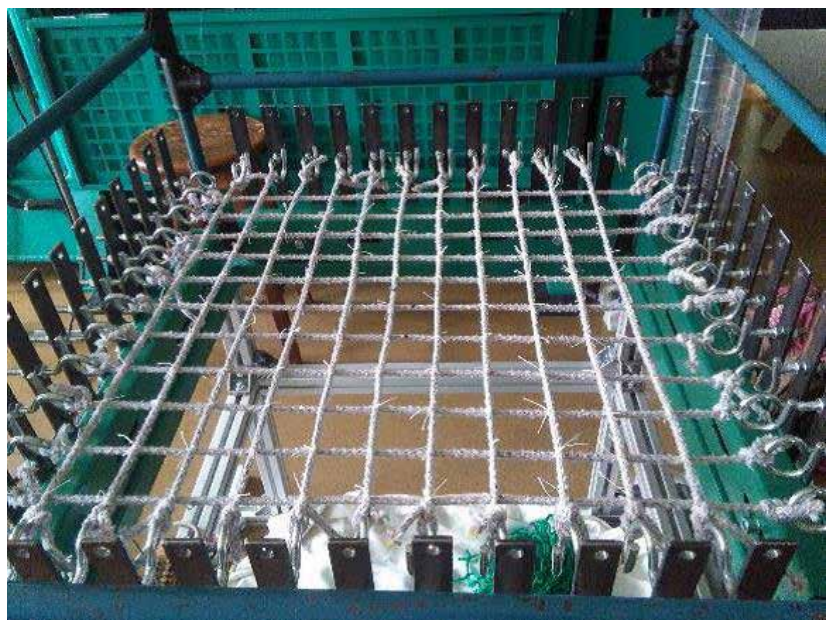

Figure 25. Verified meshes: (a) variant S1, (b) variant S2. b)

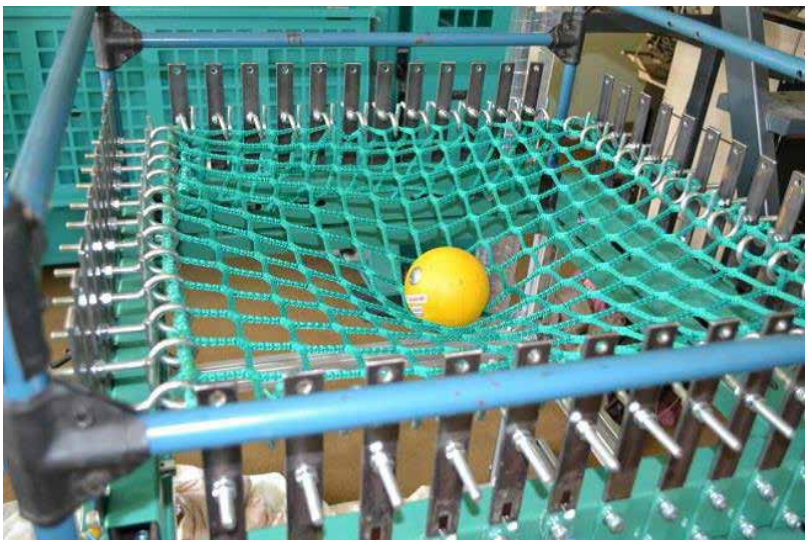

\subsection{Experimental research concerning forces measurement in strings fastening barrier meshes}

Prior to starting the testing, the measuring system should be calibrated. Twelve strain gauges recording the impact of changes in output voltage of the strain gauge bridge were subjected to calibration. The applied forces were changed by the weights applied on the strings fastened perpendicularly to the spiral hooks fixing the meshes. For each of the 12 measuring sensors, calibration graphs were determined and calibration function equations were defined (Figure 24).

The described dependencies of the measured physical quantity-force $\mathrm{F}$ in the strings and knots on the indirectly measured voltage change $U$ in the strain gauge system are linear functions in all 12 sensors. The next stage included successive fastening of three mesh variants on the holders of the measuring frame, zeroing of the sensors and implementing the load in the form of dynamic deformation of the mesh in its central point (Figure 25).

The experiment involved dropping a ball of weight $5 \mathrm{~kg}$ and a diameter of $10 \mathrm{~cm}$ onto the mesh from a height of $1 \mathrm{~m}$ and $2 \mathrm{~m}$, releasing impact energy of $49.01 \mathrm{~J}$ and $98.01 \mathrm{~J}$. After starting the SW timer, the measured voltage changes were processed in an analog-to-digital converter with a frequency of $16 \mathrm{KHz} /$ channel and then recorded in the spreadsheet of the $\mathrm{PCl}$ data archiving card.

\subsection{Analysis of measurement results}

The measurement results were recorded in the form of voltage change $U=f(t)$ and then recalculated into the function of force change in time $F=f(t)$, according to the calibration chart. Sample diagrams of dynamic forces distribution in the strings for two mesh variants S2 and S3 are shown in Figure 26. The mesh variants were fixed at $0^{\circ}$ angle meshes with square-shaped a-jour geometry, or $45^{\circ}$ angle meshes with diamond-shaped a-jour structure. For all samples, symmetrical distribution of forces was observed in individual string pairs in the measured $1 / 4$ of the mesh. The pairs are formed by strings arranged on two adjacent sides of the mesh, starting from the corner. For example, in case of the diamond-shaped mesh, when a $5 \mathrm{~kg}$ object is dropped from a height of $2 \mathrm{~m}$ (Figure 26d), the forces in individual string pairs close to the corner equal to: $1: 67.32 \mathrm{~N}$ and 1a: $50.22 \mathrm{~N}, 2: 138.24 \mathrm{~N}$ and 2a: $172.08 \mathrm{~N}, 3: 244.26 \mathrm{~N}$ and 3a: $341.1 \mathrm{~N}$, and in the central pairs of strings: $4: 343.08 \mathrm{~N}$ and 4a: $195.36 \mathrm{~N}, 5: 285.36 \mathrm{~N}$ and $5 \mathrm{a}: 347.16 \mathrm{~N}$, and $6: 370.41 \mathrm{~N}$ and $6 \mathrm{a}: 418.89 \mathrm{~N}$.

The presented regularity repeats for all measured mesh variants. The research shows that the outer strings demonstrate the lowest dynamic values of tensile forces while the middle ones shows the highest. The symmetrical distribution of forces on the perimeter of the tested mesh confirms the results of the numerical simulations carried out for the same mesh geometry and fastening method, as shown in Section 4.1. The conducted 


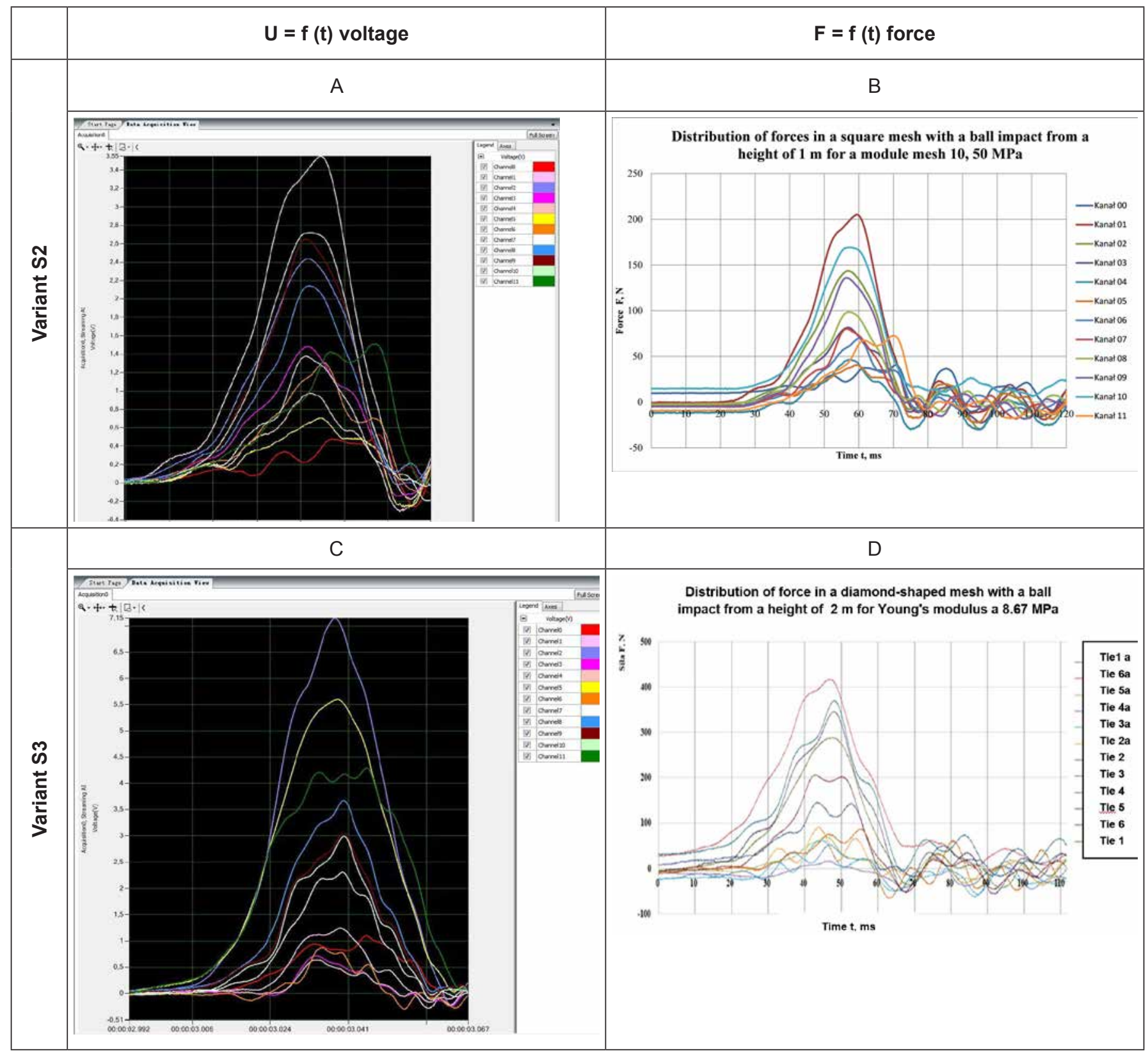

Figure 26. Dynamic forces distribution in mesh strings: (a) in volts $\mathrm{V}$ recorded in string pairs for $\mathrm{S} 2$ mesh with Young's modulus $10.50 \mathrm{MPa}$ and square a-jour geometry at ball impact from height of $1 \mathrm{~m},(\mathrm{~b})$ in string pairs for S2 mesh with Young's modulus $10.50 \mathrm{MPa}$ and square a-jour structure at ball impact from a height of $1 \mathrm{~m}$ (maximum values in individual strings: 1: $72.48 \mathrm{~N}, 1 \mathrm{a}: 40.58 \mathrm{~N}, 2: 65.36 \mathrm{~N}, 2 \mathrm{a}: 65,12 \mathrm{~N}, 3: 70.14 \mathrm{~N}$, 3a: $69.89 \mathrm{~N}, 4: 69.59 \mathrm{~N}, 4 a: 99.12 \mathrm{~N}, 5: 146.12 \mathrm{~N}, 5 a: 135.72 \mathrm{~N}, 6: 169.35 \mathrm{~N}, 6 a: 206.63 \mathrm{~N}$ ), (c) in volts V recorded in string pairs for mesh with Young's modulus $8.67 \mathrm{MPa}$ and diamond a-jour structure at ball impact from height of $2 \mathrm{~m}$, (d) in string pairs for mesh with Young's modulus 8.67 MPa and diamond a-jour geometry at ball impact from height of $2 \mathrm{~m}$ (maximum values in individual strings: 1: $67.32 \mathrm{~N}, 1 \mathrm{a}: 50.22 \mathrm{~N}$, 2: 138.24 N, 2a: 172.08 N, 3: 244.26 N, 3a: 341.1 N, 4: 343.08 N, 4a: 195.36 N, 5: 285.36 N, 5a: 347.16N, 6: 370,41N, 6a: 418.89 N).

experiment of measuring forces in the strings situated around the mesh perimeter confirmed the correctness of the construction of the measuring stand, which gives premises for empirical identification and analysis of stress distribution in the outer knots. This measuring stand is equipped with an optical system for measuring mesh deformation in the direction of the z-axis, perpendicular to the mesh surface, and can help to determine the value and surface distribution of mesh deformations. The part of the study concerning mesh deformations is not presented in this publication. What is extremely important is that the developed instrumental method of stress measurement in the mesh fastening points can serve as a useful validating tool for the results of the FEM numerical experiment in the context of optimizing mesh structures as well as their structural and material parameters.

\section{Conclusions}

1. The conducted numerical experiment for two variants of meshes with square and diamond-shaped a-jour structure showed that the distribution of stress and deformations 
in the strings, knots and in the mesh surface takes a symmetrical shape in relation to two symmetry axes perpendicular to the mesh sides. The results of this experiment were used to design a measuring stand for the evaluation of dynamic loads in the mesh samples. The sensors for measuring forces in the strings (mesh knots) were arranged only in $1 / 4$ of the measuring frame.

2. The assumptions of instrumental methodology for measuring dynamic loads of knitted barrier meshes were defined. The construction of the test stand consisted of two stages, one concerning the mechanical aspects and the other, the electronic system. Maximum values of dynamic forces in the mesh fastening strings were determined at the level of $850 \mathrm{~N}$, by the linear characteristic of the measured voltage $U$ related to the determined forces $F$. The correctness of the strain gauges construction and measurement data transmission systems was confirmed.

3. Experimental tests of multidirectional resistance to dynamic loads in the mesh fastening strings were carried out. The research included the following stages:

- Three variants of meshes were designed and manufactured, including two knitted meshes, with square and diamondshaped a-jour structure, differing in eyelet size, the thickness of the mesh arms, and structural parameters.

- The knitted meshes were produced on the warp knitting machine Karl Mayer type RL5 NF with needle gauge E12, at Knitting Machine Laboratory of the Department of Knitting Technology and Textile Machines.

- The experiment involved dropping a ball with a mass of $5 \mathrm{~kg}$ and a diameter of $10 \mathrm{~cm}$, from a height of $1 \mathrm{~m}$ and $2 \mathrm{~m}$ onto the mesh surface. The potential impact energy equaled $E p 1=49.05 \mathrm{~J}$ and $E p 2=98.1 \mathrm{~J}$.

- The conducted experiment showed that for a mesh made of polypropylene cords with a diameter equal to $\phi=4.46 \mathrm{~mm}$ and a Kevlar core, with square-shaped a-jour structure, marked as Variant 1, the highest values of impact forces were recorded, close to $537 \mathrm{~N}$. The force peaks were observed in string pairs, e.g., string 6 and $6 a(536.82 \mathrm{~N}$ and $485.70 \mathrm{~N})$, string $5 \mathrm{a}$ and 5 (395.37 $\mathrm{N}$ and $284.12 \mathrm{~N})$ string $4 \mathrm{a}$ and $4(132.12 \mathrm{~N}$ and $112.59 \mathrm{~N})$, and for the remaining string pairs: string $3: 36.14 \mathrm{~N}$, and $3 a: 35.28 \mathrm{~N}, 2: 29.36 \mathrm{~N}$, and $2 \mathrm{a}: 30.12 \mathrm{~N}$, and for string $1: 8.48 \mathrm{~N}$ and $1 \mathrm{a}: 8.58 \mathrm{~N}$, for which the lowest force values were recorded. For the knitted mesh with square a-jour geometry marked as Variant 2, hit with a ball dropped from a height of $1 \mathrm{~m}$, the maximum force values reached $207 \mathrm{~N}$, and the values recorded in string pairs were: $6 a(206.63 \mathrm{~N})$ and $6(169.35 \mathrm{~N}), 5(146.12 \mathrm{~N})$ and $5 a(135.72 \mathrm{~N}), 4 a$ and $4(99.12 \mathrm{~N}$ and $69.59 \mathrm{~N})$. When the ball was dropped from a height of $2 \mathrm{~m}$ onto a mesh with square a-jour geometry, the maximum force equaled $477 \mathrm{~N}$, and in the string pairs the following force values were recorded: in strings pair $6 \mathrm{a}$ and 6: $-476.63 \mathrm{~N}$ and $456.47 \mathrm{~N}, 5 \mathrm{a}(336.72 \mathrm{~N})$ and $5(302.12 \mathrm{~N})$ and in strings $4 \mathrm{a}$ and $4: 150.12 \mathrm{~N}$ and $96.12 \mathrm{~N}$.
- For the second mesh with square and diamond-shaped a-jour structure, marked as variant 3 , the distributions in the strings were similar to those recorded for variant 2 . The experimental tests showed that the highest force values were observed for the meshes with square-shaped a-jour structure, and the force values were lower for the mesh with diamond-shaped a-jour geometry. A pair-like forces distribution was observed in all the strings. The highest forces were recorded in the middle strings and the lowest in the outer ones (situated in the corners of the meshes).

4. The conducted experimental tests confirmed the correctness of the adopted constructional solutions of the test stand for identification of dynamic stress distribution in the mesh fastening strings. The developed instrumental method for evaluation of stress and deformation distribution in barrier meshes is a useful tool for validating the numerical analysis of mechanical properties of barrier meshes.

\section{References}

[1] Pytlik, A. (2013). Study based on "box test" of static loadcapacity of mining grids applied in the standing support and roof bolting Przegląd Górniczy. (in polish).

[2] Pytlik, A. (2013). Comparative study of load capacity of spray coatings and mesh linings by "box test" Mining natural hazards 2013, Prevention of natural hazards. Collective work edited by Józef Kabiesza. Główny Instytut Górnictwa. Katowice. s. 348-394. (in polish).

[3] Skarbøvig, N. M., Lamos, A. W., Lamos, R. A. (2011). Mine safety net development and applications. The Journal of The Southern African Institute of Mining and Metallurgy, 111.

[4] Rotkegel, M. (2014). The impact of the method of installing mesh linings on their work. Przegląd Górniczy, 3. (in polish).

[5] Pytlik, A. (2013). Research on shotcrete and thin-walled spray membranes using the box test method. Przegląd Górniczy, 12. (in polish).

[6] Morel, J. C., Gourc, J. P. (1997). Mechanical behavior of sand reinforced with mesh elements. Geosynthetics International, 4(5), 481-508

[7] Bui, H. H., Fukagawa, R., Sako, K., Ohno, S. (2008). Lagrangian meshfree particles method (SPH) for large deformation and failure flows of geomaterial using elasticplastic soil constitutive model. International Journal for Numerical and Analytical Methods in Geomechanice.

[8] Ranga Raj, R., Velmurugan, R., Dinesh, C., Balaji, S. (2015). Experimental test of stainless steel wire mesh and aluminium alloy with glass fiber reinforcement hybrid composite. Journal of Engineering Research and Applications, 5(5, Part-6), 80-88.

[9] Morton, E., Villaescusa, E. (2008). Static and dynamic testing of steel wire mesh for mining applications of rock surface support. In: Conference: 6th International Symposium On Ground Support in Mining and Civil Engineering Construction, Cape Town, South Africa.

[10] Morton, E., Villaescusa, E. (2007). Testing and analysis of steel wire mesh for mining application of rock surface support. Conference: ISRM Congress, Lisbon. 
[11] Morton, E., Villaescusa, E. (2016). Dynamic Testing of Combined Rock Bolt and Mesh Schemes. Conference: Seventh International Conference \& Exhibition on Mass Mining, Sydney.

[12] Brändle, R., Rorem, E. A., Fischer, G. (2017). Full-scale dynamic tests of a ground support system using hightensile strength chain-link mesh in El Teniente mine, Chile, Engineering.

[13] Catalogue GEOBURGG BRUGG - 100 kJ: TXI-010 rockfall protection barrier: Because even small events can have devastating effects.

[14] Pytlik, A., Lankocz, T., Cieślik, J., Pelc, R. (2016). Comparative study of steel and composite mining meshes. Przegląd Górniczy (in polish).

[15] Player, J. R., Morton, E. C., Thompson, A. G., Villaescusa, E. (2008). Static and dynamic testing of steel wire mesh for mining applications of rock surface support. In: 6th International Symposium on Ground Support in Mining and Civil Engineering Construction.

[16] Balasingam, M., Shanzhi, S., Navaratnarajah, S., Hattamleh, O. A., Badger, T. C., Lowell, S. M., Duffy, J. D. (2005). Analysis and Design of Wire Mesh/Cable Net Slope Protection, Design Guidelines for Wire Mesh/Cable Net Slope Protection, (WA-RD 612.2).

[17] Catalogue GEOBURGG BRUGG- The GBE barrier series: protection against impact energies from $100-8,000 \mathrm{~kJ}$.

[18] Catalogue GEOBURGG BRUGG- 250-5000kJ: RXI and $A X I$ rockfall barriers stop rocks that would even overwhelm concrete galleries.

[19] Mrozik, M., Sierant, J. (2009). Nailed escarpments on modernized roads S1, S7 and DK 69 Nowoczesne Budownictwo Inżynieryjne September - October 2009r. (in polish).
[20] Geobrugg Partner in Poland: GBE barriers made of high tensile wire - Economical solution fully protecting against rock chippings. Nowoczesne Budownictwo Inżynieryjne January-February 2016r. (in polish).

[21] Catalogue SNA 2017r.: Safety Nets Australia.

[22] McCann, P. (2011). Evaluation of safety nets by experiment. Health and Safety Laboratory for the Health and Safety Executive.

[23] Huck safety net catalog - safety netting and bridge platforms.

[24] Agreement for safety in the construction industry: Collective work: safety nets. Standard BHP 18.2.

[25] Escárpita, D. A. A., Elizalde, H., Cárdenas, D., RamirezMendoza, R. A. (2012). Biaxial tensile strength characterization of textile composite materials. In: Composites and their properties, Chapter 5.

[26] Bridgens, B., Umaña, G., Lin, P. (2012). Inter-laboratory comparison of biaxial tests for architectural textiles. Journal of the Textile Institute.

[27] Catalogue 2018l19- Accurate Safety- Safety nets.

[28] Szałek, B., Mikołajczyk, Z., Pieklak, K., Michalak, A. (2017). Assumptions of empirical verification process of strength model of knitted barrier meshes. In: XVIII Scientific Conference of the Faculty of Material Technologies and Textile Design.

[29] Advantech company product card. Web site: www. advantech.com/products [Accessed 05.04.2019].

[30] Bridgens, B., Gosling, P., Jou, G.-T. (2015). Inter-laboratory comparison of biaxial tests for architectural textiles.

[31] Web site: http://www.tenmex.pl/ [Accessed 05.04.2019.]. 